Purdue University

Purdue e-Pubs

CTRC Research Publications

Cooling Technologies Research Center

$2-5-2001$

\title{
Recent Advances in the Modeling and Applications of Nonconventional Heat Pipes
}

S V. Garimella

Purdue University, sureshg@purdue.edu

C. B. Sobhan

Follow this and additional works at: http://docs.lib.purdue.edu/coolingpubs

Garimella, S V. and Sobhan, C. B., "Recent Advances in the Modeling and Applications of Nonconventional Heat Pipes" (2001). CTRC Research Publications. Paper 13.

http://docs.lib.purdue.edu/coolingpubs/13

This document has been made available through Purdue e-Pubs, a service of the Purdue University Libraries. Please contact epubs@purdue.edu for additional information. 
Running Title: Recent Advances in Nonconventional Heat Pipes

\title{
Recent Advances in the Modeling and Applications of Nonconventional Heat Pipes ${ }^{1}$
}

\author{
Suresh V. Garimella ${ }^{2}$ \\ Cooling Technologies Research Consortium \\ School of Mechanical Engineering \\ Purdue University \\ West Lafayette, IN 47907-1288 USA \\ Tel: (765) 494-5621 Fax: (765) 494-0539 \\ sureshg@ecn.purdue.edu

\section{B. Sobhan} \\ Department of Mechanical Engineering \\ Regional Engineering College \\ Calicut, Kerala 673601 INDIA \\ Tel: +(91) 495286437 \\ sobhan@vishak.reccal.ernet.in
}

\footnotetext{
${ }^{1}$ For publication in Advances in Heat Transfer, Vol. 35

${ }^{2}$ Author to whom correspondence should be addressed
} 


\section{TABLE OF CONTENTS}

I. Introduction

II. Thermal Analysis

A. Conventional Designs

B. Nonconventional Designs

B.1. Flat Heat Pipes

B.2. Concentric Annular Heat Pipes

B.3. Rotating Heat Pipes

B.4. Disk-Shaped Heat Pipes

B.5. Reciprocating Heat Pipes

B.6. Gas-Loaded Heat Pipes

B.7. Other Designs

III. Thermodynamics and Fundamental Aspects

IV. Heat Pipe Start-up From the Frozen State

V. Discrete Heat Sources at the Evaporator

VI. Heat Pipe Applications

VII. Micro Heat Pipes

VIII. Thermosyphons

IX. Capillary Pumped Loops

X. Inventions and Patents

XI. Closure

Acknowledgement

Nomenclature

References 


\section{INTRODUCTION}

The use of heat pipes and thermosyphons is becoming widespread in a large number of applications, as these devices are generally passive in their operation and provide effective heat transport with minimal losses. Practical applications range from aerospace engineering to energy conversion devices, and from electronics cooling to biomedical engineering. One of the drivers for heat pipe development has been the need to reliably manage thermal dissipation in increasingly miniaturized and higher-density microelectronic components, while maintaining device temperatures to specification. Many different types of heat pipes have been developed in recent years to address electronics thermal management problems, as well as a host of other applications, and have shown promising results.

Extensive research on heat pipes and thermosyphons has been reported during the past decade. Effective design of heat pipes, based on their operating limitations and depending on analytical and experimental results and parametric studies has been the object of attention of many investigators. Various new concepts involving miniature forms of heat pipes and thermosyphons, micro heat pipes and other nonconventional designs have been proposed, and the operation of these devices has been analyzed and tested. Increasingly realistic assumptions have been used in the modeling of heat pipes, supported by experimental investigations.

While the vapor flow and heat transfer processes in heat pipes have been studied in the past, the analysis of these processes coupled with liquid flow in the wick structure has received a lot of attention more recently. Simplified conduction models and transport equations have been used for the liquid flow in heat pipe wicks, with the wick structure generally being treated as a porous medium. Theoretical and experimental approaches have been employed for computing, visualizing and measuring the capillary meniscus at the wick-vapor boundaries. In addition, 
efforts for identifying the major limitations of heat pipe operation and for quantifying the maximum heat transport capabilities theoretically and experimentally have been reported. A number of recent publications have dealt with transient analyses and heat pipe start-up. Thermodynamic aspects of heat pipe operation, including meniscus formation have also been explored. Analyses of vapor and liquid flow dynamics in heat pipes incorporating thermodynamic considerations have been presented.

Flat-plate and other nonconventional designs such as disk-shaped, rotating, and reciprocating heat pipes, as well as thermosyphons, have also received attention. Multidimensional analyses of the vapor and wick regions in such heat pipes have been reported wherein the temperature, pressure and velocity fields in the vapor and liquid as well as the maximum heat transport capabilities are obtained. Miniature forms of heat pipes and thermosyphons for use in electronics cooling applications have also been explored.

Micro heat pipes have been suggested as effective devices for cooling electronics, and methods for the development, analysis and testing of micro heat pipes have been discussed in detail in the literature. Fundamental studies of the fluid flow and heat transfer mechanisms in micro channels and their application to understanding the physics of micro heat pipes are also available.

Recent advances in the analysis and understanding of heat pipes are reviewed here, with a special emphasis on investigations reported over the last decade. While conventional heat pipes are briefly discussed, the focus is on nonconventional designs, including heat pipes that are flat, concentric annular, rotating, disk-shaped, reciprocating, or gas-loaded. Both experimental and theoretical approaches are included. Special conditions such as start-up transients and operation with discrete heat sources at the evaporator are discussed. A majority of the studies have been 
aimed at electronics cooling applications, although a number of other applications have also been studied. Micro heat pipes, thermosyphons and capillary pumped loops are surveyed. This review also includes a discussion of the recent patents and inventions in this area.

\section{THERMAL ANALYSIS}

Theoretical and experimental investigations that provide insight into the physics, design considerations, and operating limits of various types of conventional heat pipes as well as nonconventional designs such as annular, flat and disk-shaped, and gas-loaded, rotating and reciprocating heat pipes (where novel methods are used to achieve or improve fluid transport) are discussed in this section.

\section{A. Conventional Designs}

A variety of theoretical analyses in the literature have provided temperature, pressure and velocity distributions in transient and steady-state operation of heat pipes. Transient, compressible one-dimensional vapor flow in a cylindrical heat pipe was analyzed by Jang et al. [1]. Transient vapor flow dynamics were predicted at subsonic, sonic and supersonic speeds, and at high mass flow rates and high temperatures. Friction coefficients at the interface were incorporated from existing two-dimensional numerical results. Injection and suction terms were included in the governing equations. Solutions were obtained using the implicit non-iterative Beam Warming finite difference method. The numerical results as shown in Figure 1 for a sodium heat pipe were compared with experimental data [2] on vapor flow in a cylindrical heat pipe simulated using a porous pipe with injection and suction of air, and also with data on actual vapor flow in cylindrical heat pipes [3]. 
Bowman et al. [4] presented a one-dimensional model in which the vapor flow, treated as a saturated vapor and not an ideal gas, was assumed to be incompressible in space but compressible in time. This model was improved by Bowman and Beran [5] who used a more accurate closure relationship between vapor density and vapor temperature in solving the mass conservation equation. This relationship expressed the density as a series function of the saturated vapor temperature with the coefficients having been obtained by curve-fitting saturated vapor data. An implicit solution method was used for solving the governing equations.

Issacci et al. [6] used a two-dimensional, transient, compressible viscous flow model and a finite-difference solution to analyze the vapor dynamics during heat pipe start-up. Transient variations of pressure, velocity and friction factor were obtained. The calculated pressure drops for the transient period were found to be significantly higher than the steady-state values, exhibiting a nearly periodic oscillation while converging towards a steady state. This phenomenon was explained in terms of the multiple wave reflections observed in the evaporator and adiabatic regions during the start-up transient. The transient variations of the vapor temperature and pressure are shown in Figure 2. The average friction factor at the liquid-vapor interface was found to be significantly higher during the transient than at steady state, especially for higher input fluxes. A reversal of flow was noticed in the adiabatic region during the transient period. High heat fluxes of the order of $100 \mathrm{~W} / \mathrm{cm}^{2}$ were used in the analysis.

Zuo and Faghri [7] developed a heat pipe model with quasi-steady, one-dimensional vapor flow and transient, two-dimensional heat conduction in the wall and wick. The vapor flow was solved using the SIMPLE algorithm and the wick and wall regions were solved using the boundary element approach. This work essentially compared the effectiveness of using finite differences versus boundary elements for the solution of heat conduction in the wall and wick 
regions. A hybrid FDM/BEM method was found to offer a significant reduction in the computational time. A two-dimensional numerical analysis of the transient behavior of a cylindrical heat pipe was performed by Cao and Faghri [8]. Conservation equations were solved using an effective thermal conductivity for the screen wick. The saturation temperature was obtained from the saturation pressure at the liquid-vapor interface using the Clausius-Clapeyron equation; the equation of state for an ideal gas was applied in the vapor core.

A two-dimensional heat pipe transient analysis model was developed by Tournier and ElGenk [9]. Liquid compressibility, energy and momentum discontinuities at the liquid-vapor interface, and determination of the radius of curvature of the liquid meniscus at the interface were incorporated into the model, in addition to the effects of liquid pooling. Conservation equations were solved in the vapor region, while the Brinkman-Forchheimer extended Darcy flow model was employed for the wick region. The vapor in the core was assumed to be saturated, obviating the need for a consideration of the energy equation. At the liquid-vapor interface, conservation of mass was enforced along with a no-slip condition and an enthalpy jump due to evaporation/condensation. Numerical solutions were obtained by a predictorcorrector method. Variations of the effective thermal power throughput and vapor temperature with time were obtained. Axial variations of the wall and vapor temperatures and the normalized void fraction in the wick at various locations were computed. An important contribution of this paper was the identification of the formation and disappearance of the liquid pool, shown in the plots for the early transient response. The extent of the liquid pool, along with the evaporation and condensation rates were determined with respect to axial position as a function of time. Figure 3 shows the transient variation of the extent of the liquid pool at the condenser from [9]. 
Chang and Chow [10] analyzed the transient response of a liquid metal heat pipe using a three-dimensional model for the wall and the wick, under the assumption that the liquid velocity in the wick was low, and the heat transfer through the wick was by conduction only. A onedimensional model was used for the vapor flow. Transient variations of the surface temperature were compared with experimental results performed on a sodium heat pipe. The condenser was operated under transient conditions, and a reverse heat load was used in some of the experiments.

Experimental studies in the literature have generally attempted temperature and pressure measurements and visual observation of the fluid flow phenomena in heat pipes. Experimental verification of predicted maximum heat transport limits, and evaluation of the performance of heat pipes under various operating conditions, have also been presented.

Yamamoto et al. [11] conducted transient experiments on stainless steel-mercury heat pipes, with the evaporator heated in a furnace. Results were presented in terms of temperature distributions and boiling and condensation curves. The mercury heat pipe was found to exhibit good performance except during start up. However, the material compatibility between the stainless steel container and mercury was not satisfactory, as revealed by visual observation using SEM and $\mathrm{X}$ ray microanalysis.

Copper-water heat pipe systems with double-layered copper screen wicks were investigated by El-Genk and Huang [12] to determine their transient response to step changes in input power. The evaporator section was uniformly heated and the condenser section was convectively cooled at different cooling rates. Spatial and temporal variations in the temperature of the wall as well as in the vapor were measured in addition to the effective power throughput. Time constants for transients in the vapor temperature and power throughput were determined as functions of the power input and the liquid mass flow rate in the cooling jacket of the condenser. 
El-Genk et al. [13] performed experiments on a cylindrical copper-water heat pipe in an inclined position. The effect of the inclination angle at various power inputs and cooling rates was assessed, using the time constants during heat up and cool down. The time-dependent vapor and wall temperature data were used to benchmark their two-dimensional heat pipe transient analysis model.

Experiments were performed by Huber and Bowman [14] on copper-water heat pipes at various inclination angles to determine the effect of vibration on the capillary limit. Temperatures, vibration characteristics and coolant flow rates were measured. Longitudinal vibration was found to cause a decrease in the capillary heat transport limit at certain amplitudes and frequencies.

A transient experimental and numerical study of the performance of a circular stainless steel-ammonia loop heat pipe was reported by Wirsch and Thomas [15]. The heat transfer coefficient at the evaporator was experimentally determined. A two-dimensional conduction model for the evaporator wall was solved using finite elements, and the characteristics of the loop heat pipe explored.

The evaporative heat transfer in a cylindrical grooved heat pipe was studied by Kobayashi et al. [16]. The liquid meniscus was divided into a macro and a micro region in the theoretical analysis: the macro region covered the liquid meniscus where conventional heat and mass transfer were expected to take place, while the micro region included the narrow meniscus region close to and in contact with the wall where intermolecular forces would affect transport. The thickness of the micro region was measured by optical means and its magnitude was explained in terms of the proposed theory. An interesting result was that one-third of the total 
heat supplied was transported though the micro region even though this region occupied only one-hundredth of the total meniscus area.

\section{B. Nonconventional Designs}

\section{B.1. Flat Heat Pipes}

Flat heat pipes are especially useful in applications where space considerations are important as they can effectively replace a number of cylindrical heat pipes. Asymmetrical heating of the flat heat pipe (from one side only) was analyzed using an integral method by Vafai and Wang [17], to obtain the pressure, temperature and velocity distributions. A nondimensional formulation of the governing equations was used with the porous wick represented by Darcy's law. Calculations were performed for heat pipes with the container and wick made from aluminum and with heavy water as the working fluid. Axial distributions of the vapor and liquid pressures obtained by this analysis are shown in Figure 4. Zhu and Vafai [18] studied the startup transient characteristics of an asymmetrical flat plate heat pipe, using transient heat conduction equations for the heat pipe wall and wick regions, and a pseudo-three-dimensional approximation for the vapor region.

A transient two-dimensional analysis of the vapor core and wick regions of a flat heat pipe was performed by Unnikrishnan and Sobhan [19]. For modeling the porous wick, the momentum equations were modified to account for the effect of the solid boundary and the inertial forces on the fluid flow [20]. The energy equation for the porous wick region included convection terms. Transient and steady-state variations of temperature, pressure and velocity were presented to illustrate the effect of different wick porosities. Figure 5 shows two typical plots of the transient distribution of the field variables obtained from this analysis, which 
demonstrate that the effect of wick porosity in the vapor core is of secondary importance, whereas this effect is more pronounced in the wick, especially in the evaporator and condenser regions.

A computational model for the analysis of flat heat pipes was developed by Sobhan et al. [21], which took into account the effects of conduction through the wall and wick which in turn result in heat flow into the interior through the externally adiabatic section and affect the velocity distributions in the wick and vapor. The heat removal capability of the heat pipe was contrasted to that of a copper heat sink with dimensions equivalent to those of the heat pipe wall, and it was found that the temperature drop along the heat pipe was reduced by $83 \%$ compared to the copper heat sink. The effects of variations in the wall thickness, wick porosity and evaporator heat flux on the performance of the flat heat pipe were explored using this model by Vadakkan et al. [22].

Khrustalev and Faghri [23] discussed the boiling and capillary limitations of a miniature, axially grooved flat heat pipe, with its performance enhanced by applying a porous copper coating on the surface between the grooves. The maximum heat transport capacity, incorporating heat transfer coefficients for the enhanced surfaces, was computed. Variations of the maximum heat flow rate with respect to the operating temperature, with and without the porous coating, were compared as shown in Figure 6, showing a significant enhancement predicted due to the presence of the porous coating.

Experiments on a flat plate heat pipe used as an alternative to a solid metal heat sink for electronics cooling were reported by Um et al. [24]. An aluminum heat pipe with a glass top and stainless steel screen wick on one side was considered, with a dielectric fluid (FC-72) as the working medium. Effects of gravity on the temperature distribution and heat transport capacity were studied. 


\section{B.2. Concentric Annular Heat Pipes}

A concentric annular heat pipe utilizes the annulus between two concentric tubes as the vapor space, and features a capillary wick on either side of the annulus. The advantage is that both the inside and outside walls can be used for transferring heat into the evaporator. The design, testing and analysis of the capillary limit in copper-water concentric annular heat pipes was discussed by Faghri and Thomas [25]. The axial temperature variation and maximum heat transport capacity in such a design were compared with those for a conventional heat pipe. Experimental measurements revealed that the annular heat pipe was capable of providing a maximum heat transport capacity as high as two times that of a conventional cylindrical heat pipe at comparable operating temperatures. The temperature variation in the evaporator section was found to be lower for the concentric annular heat pipe, whereas in the condenser section, the temperature drop was larger for the annular case. The evaporator and condenser performance characteristics from this work are shown in Figure 7. The variation of maximum heat input as a function of tilt angle was also reported in the paper. Two analyses of the concentric annular heat pipe were presented by Faghri [26]: a one-dimensional model was developed for compressible flow to arrive at the axial variations of Mach number, pressure and temperature; and a twodimensional approach was used for treatment of the vapor as an incompressible flow in which uniform blowing and suction rates were assumed over the heating and cooling sections, which were then related to the local heat transfer rates per unit length. 


\section{B.3. Rotating Heat Pipes}

Rotating heat pipes utilize centrifugal force to accomplish the transport of the liquid phase. Laminar, steady, incompressible vapor flow in axially rotating heat pipes was analyzed by Faghri et al. [27]. Normalized velocity components and temperature variations along the radius and length were obtained. The axial coefficient of friction was plotted along the length, and was found to decrease with an increase in the rotational speed; as the radial Reynolds number increased, the magnitude of friction coefficients decreased. The tangential coefficient of friction remained almost constant along the axial direction at low radial Reynolds numbers, but increased rapidly in the condenser section at high Reynolds numbers. The rotational speed and radial Reynolds number were found to have a strong influence on the predicted velocities and pressures. At high rotational speeds, a central core with reversed flow in the axial direction was observed and was attributed to the reduced pressure at this location. A transient, twodimensional simulation of the rotating heat pipe, with an axisymmetric formulation which accounted for the thin liquid condensate film on the inner surface of the wall, was used by Harley and Faghri [28] to arrive at transient variations of the temperatures and velocities.

Lin and Groll [29] performed a two-dimensional analysis of the stability of annular flow in a rotating heat pipe with a cylindrical wall. The mismatch between the asymptotic solutions obtained for the Froude number and the experimental data in certain ranges was explained in terms of the axial wave observed at the interface between the two phases. A modified expression was proposed for the critical Froude number for the collapse of the annular liquid layer in inviscid flow, based on visual observation of the axial wave crest:

$$
F r=\frac{3}{\left(1-D_{r}\right)^{2}}
$$


A theoretical analysis of the steady-state operation of a rotating miniature heat pipe with a grooved inner wall was reported by Lin and Faghri [30]. The momentum equation for the liquid was modified to incorporate a centrifugal force term. The conservation equations were solved using finite elements and an expression for the liquid friction coefficient in the groove was obtained. It was observed that the heat pipe performance improved with an increase in the rotational speed and the operating temperature.

Lin and Faghri [31] conducted experiments on a rotating stepped-wall heat pipe to study the region of hysteretic annular flow, which is the rotational-speed range between the onset and collapse of annular flow. Condensation heat transfer coefficients were obtained as a function of heat rate and rotational speed and compared with values predicted theoretically. It was concluded that the hysteretic annular flow was a stable flow pattern, and resulted from secondary flow in the liquid pool. The condensation coefficients in the hysteretic annular flow region were found to be lower relative to those in the other regions. Variation of the condensation coefficient with respect to the heat rate was found to be significantly more pronounced at the higher rotational speeds, as seen in Figure 8.

An axially rotating miniature heat pipe with a polygonal inner wall featuring axial triangular grooves was analyzed by Lin and Faghri [32]. Effects of the disjoining pressure, surface tension and centrifugal force on the flow were discussed. The influence of superheat on the apparent contact angle and the evaporative heat transfer coefficient in the micro region was explored. The centrifugal force was found not to significantly affect the liquid film flow and evaporator heat transfer into the micro region.

Ponnappan et al. [33] experimented with high speed rotating heat pipes with methanol and water as working fluids, to study the performance at various rotational speeds. The axial 
temperature profiles were obtained for air- and oil-cooling of the condenser at various coolant flow rates. The performance of the heat pipe was found to be inferior to design values, and this was attributed to the poor efficiency of condenser cooling. Theoretical and experimental heat transfer capacities of the water and methanol heat pipes were compared. It was found that the agreement between theoretical predictions of [34] and the experimental results was poor, the deviation being greater in the case of the water heat pipe. The deviation was explained as being due to the experimental limitation caused by the oil cooling at the condenser that does not match with the design heat transport, and also due to the limitations from the Nusselt-type condensation theory used in the theoretical predictions, which may not be applicable for the high speed flow regime of the experiments.

\section{B.4. Disk-Shaped Heat Pipes}

Disk-shaped heat pipes for application in boron neutron capture therapy have been investigated in a series of papers. Steady incompressible vapor and liquid flow in a disk-shaped heat pipe with divergent vapor channels and a vertical as well as lateral wick structure were analyzed by Vafai et al. [35]. Continuity and momentum equations were used to model the vapor flow with the assumption of a parabolic profile for the radial velocity, while the mass conservation equation and Darcy's law were utilized to solve for flow in the wick region. The maximum heat transport capacity based on the capillary limitation was obtained. The effects of varying the thickness of the vapor channel and the wick on the performance of a disk-shaped and rectangular flat heat pipe were compared. The disk-shaped heat pipe showed more uniform temperature distributions in the vapor. The results showed that the disk-shaped heat pipe, while utilizing a smaller surface area, increased the heat transfer capability by up to $15 \%$ when 
compared to the rectangular heat pipe. The analytical model developed for the vapor and liquid flow in the disk-shaped heat pipe was used to study the influence of several design parameters by Zhu and Vafai [36]. The criteria for capillary and boiling limitations were established for the disk-shaped heat pipe, and the maximum heat transfer capacity was predicted based on the capillary limitation. The influence of the number of internal channels, and the thickness and shape of the top, bottom and vertical wicks on the performance was investigated. Variations in the maximum heat transfer rate as a function of the divergence angle of the vapor flow channel and the physical parameters of the wick were presented.

Disk-shaped heavy water heat pipes were investigated using a boundary layer approximation by Zhu and Vafai [37]. The vapor flow was considered to be steady and incompressible, and it was assumed that vapor injection and suction in the vertical wick were negligible. For the analytical solution, the radial velocity profile was approximated by a thirdorder polynomial; the analysis was performed for different values of disk radius, divergent flow channel angle, and injection Reynolds number to obtain the vapor velocity and pressure variations. It was found that the pressure variations in the angular and transverse directions for a disk-shaped heat pipe were small. Back flow was observed at the top entrance of the condensation zone for injection Reynolds numbers (based on vapor injection velocity and vapor channel height) of 50 and more.

An analytical model for the start-up transients in disk-shaped heat pipes with asymmetrical heating was proposed by Zhu and Vafai [18]. Integral solutions were obtained in the wall and wick with an approximation for the temperature distribution in the form of a secondorder polynomial function. The differential equations for mass and momentum conservation were numerically integrated in the vapor region, assuming a liquid-vapor interface temperature at 
each time step. The vapor phase was assumed to be saturated, and did not require the solution of an energy equation. Transient temperature, velocity and pressure distributions for both heat pipes were obtained. Variations of the power throughput with respect to time were also plotted. Transient variations of the power throughput and temperature for the disk-shaped heat pipe obtained in this work are shown in Figures 9 and 10.

\section{B.5. Reciprocating Heat Pipes}

A reciprocating heat pipe utilizes the impinging effects of the working fluid brought about by reciprocal motion to enhance performance. The application of a reciprocating heat pipe in cooling the piston of heavy-duty diesel engines, and its thermal analysis, were discussed by Cao and Wang [38]. Experimental observations were made with a transparent heat pipe without heat input in order to demonstrate the liquid impingement against the top wall as well as the liquid motion inside the reciprocating heat pipe. Thermal tests were conducted on copper-water reciprocating heat pipes. It was concluded that a much lower piston temperature could be obtained with the piston cooled by a reciprocating heat pipe than under normal operating conditions for the same amount of heat dissipation; the use of a reciprocating heat pipe yielded a heat dissipation rate that was eight times higher at the same temperature level.

A theoretical and experimental investigation of reciprocating heat pipes was reported by Ling et al. [39], who presented semi-empirical correlations for their dimensionless temperature distribution and effective thermal conductance. It was found that the liquid impingement had a significant effect on the temperature drop along the length of the heat pipe. A liquid impingement number was defined, which takes a larger value when the temperature drop along the heat pipe is larger. Effects of the fluid charge ratio (ratio of liquid charge volume to heat 
pipe volume) on the heat pipe performance (temperature and effective conductance) were determined experimentally. The influence of the frequency of the reciprocating motion on the temperature drop and effective thermal conductance, as well as their dependence on heat pipe diameter and heat input value were also obtained. A comparison of the semi-empirical correlation and the experimental data from this work is shown in Figure 11. It was found that the experimental data were collected to within $30 \%$ by the correlation.

\section{B.6. Gas-Loaded Heat Pipes}

Inclusion of a noncondensible gas in the vapor core of a heat pipe provides a means to control its performance, through control of the amount of gas included. Gas-loaded heat pipes are variable-conductance devices which offer a nearly constant heat flux and isothermal operation as heat load increases, due to the compression of the noncondensible gas in the condenser and the resulting increase in the surface area for heat transfer. Analysis of gas-loaded heat pipes involves a solution of the appropriate vapor-gas diffusion model in addition to the governing equations for flow and heat transfer.

Double-diffusive convection in a variable-conductance, gas-loaded heat pipe due to the combined effects of temperature and concentration gradients was analyzed by Peterson and Tien [40]. A dimensionless species equation based on molar properties, but independent of average molar velocity, was derived, which, along with dimensionless conservation equations, was used to analyze a two-dimensional planar heat pipe. The boundary conditions for the conservation equations were obtained by a solution of the species equation. The results of the analysis included velocity and concentration fields and the variation with Rayleigh number of the gas flux at the gas-vapor interface. The effect of Rayleigh number on the total heat transfer was obtained 
for different values of inclination angle and nondimensional molecular weight of the gas. The redistribution of the gas within the condenser did not have a significant effect on the overall condensation heat transfer. Results from the numerical simulation were presented along with experimental measurements on a cylindrical helium-water system. The iso-concentration profiles obtained from the numerical simulation of a planar heat pipe were compared with experimental results for a cylindrical case as shown in Figure 12.

A transient two-dimensional analysis of a gas-loaded heat pipe was presented by Harley and Faghri [41]. A simplified conduction model was used in the wick region, and the vapor core was analyzed using conservation equations for a mixture of sodium vapor and argon. A selfdiffusion model was used to account for the inter-species heat transfer occurring by means of vapor-gas mass diffusion. The liquid-vapor interface was assumed to be impermeable to the noncondensible gas. The Clausius-Clapeyron equation was used to determine the interface temperature as a function of pressure. The interfacial velocity was determined from the imposed heat transfer rate at the evaporator. Transient wall temperatures as well as the temperature, pressure and axial velocity profile at the centerline of the vapor core were obtained. The addition of the noncondensible gas was seen to increase the transient start-up period. It was concluded that the steady-state operation of gas-loaded heat pipes depends heavily on the mass of the noncondensible gas introduced; a reduction in the wall and vapor temperatures in the condenser results as the mass of the gas is increased.

Ponnappan and Chang [42] experimentally studied the start-up performance of a liquid metal heat pipe in a gas-loaded mode of operation, using argon gas. The start-up behavior in the gas-filled mode was found to be smooth (no temperature spikes at the evaporator) compared to the near-vacuum operation of the heat pipe. Chung and Edwards [43] presented a theoretical 
analysis of the moving gas-vapor fronts in a gas-loaded heat pipe. Axial temperature profiles were derived and incorporated into the model for transient operation. Experiments were performed on a stainless steel-ammonia system with an actively controlled gas reservoir, and the start-up transient temperature history was compared with analytical predictions. The theoretical results were found to agree fairly well with the experimental data, except at the point where the gas front entered the condenser from the adiabatic section; at this location, the model showed a more abrupt variation. The motion of the gas front during the transient period was found to have a significant effect on the axial temperature profile, and it was suggested that the influence of this varying profile on axial conduction should be included in heat pipe transient models.

\section{B.7. Other Designs}

Besides the designs discussed in the foregoing, various nonconventional designs of heat pipes suitable for specific applications have also been considered in the literature. Special shapes and methods of operation are employed in these heat pipes.

Heat pipes designed for transferring heat from the leading edge of hypersonic-vehicle wings which are subjected to intense aerodynamic heating were analyzed by Cao and Faghri [44]. These heat pipes transfer the intense aerodynamic heating at the leading edge of the wings to a condenser where the heat is rejected by radiation or convection. The numerical simulation included a consideration of capillary and sonic limits in the wick structure. The vapor flow was modeled as being transient, compressible and quasi-one-dimensional with radial injection and suction velocities included; the mass flux of vapor was evaluated using an interfacial energy balance. Friction coefficients for the evaporator and condenser were expressed as functions of the cross-sectional geometry. The wick was considered as isotropic and homogeneous, and its 
temperature distribution was considered to be independent of the liquid flow. Extensions to this work on the analysis of the wing leading edge as well as nose-cap heat pipes with a generalized finite-difference computational model was reported by Cao and Faghri [45]. The analysis considered a design in which, in addition to the radiation heat transfer from the outer wall to Space, the inner wall of the vapor chamber also transferred heat to a hydrogen-cooled heat exchanger by radiation. Expressions for capillary and boiling limits were derived. Transient variations of the surface temperature of the outer shell and the axial vapor flow Mach numbers were obtained. Steady-state pressure distributions were also presented.

Helically grooved copper heat pipes with ethanol as the working fluid were tested under centrifugal motion by Thomas et al. [46] in order to study the effects on the capillary limit of body forces induced by transverse acceleration. Information on the dry out, circumferential temperature uniformity, heat loss to the environment, thermal resistance and capillary limit was obtained. As shown in Figure 13, the measured thermal resistance was found to generally decrease with an increase in heat transport; at the commencement of dry out $\left(\mathrm{Q}_{\mathrm{t}} \approx 50 \mathrm{~W}\right)$, however, the resistance was seen to increase. There was also a five-fold increase in the capillary limit when the radial acceleration was increased from 0 to $6 \mathrm{~g}$, which was attributed to the faster return of the working fluid to the evaporator section. A qualitative study on a copper-ethanol heat pipe with straight axial grooves with radial accelerations of zero and $10 \mathrm{~g}$ and a heat input of $10 \mathrm{~W}$ revealed that there was no significant improvement in the performance with an increase in radial acceleration. A mathematical model was developed to predict the capillary limit of the helically grooved heat pipe subjected to a transverse body force. The effects of temperaturedependent coolant properties and the geometry of the heat pipe and grooves were considered in 
the model. The capillary limit predicted by the model was found to over predict experimental data by up to $50 \%$, even though the trends were qualitatively similar.

Experiments were performed by Bryan and Yagoobi [47] on the enhancement using electrohydrodynamic (EHD) pumping of the heat transport capacity of a monogroove heat pipe (with the vapor and liquid channels interconnected to form a single groove). The EHD pump was located in the liquid channel in the adiabatic section of the heat pipe. Refrigerant R-123 was used as the working medium. Enhancements of the order of $100 \%$ were achieved in the heat transport capacity using the EHD pump. Transient variations of the vapor and liquid temperatures in the evaporator were obtained as shown in Figure 14, depicting the effects of EHD pumping.

\section{THERMODYNAMICS AND FUNDAMENTAL ASPECTS}

A thermodynamic approach to analyzing transport in heat pipes has been employed in several studies in the literature. Richter and Gottschlich []48 represented the operation of the heat pipe as a thermodynamic cycle, in which thermal energy is converted into kinetic energy. The basic cycle is shown as a temperature-entropy diagram (Figure 15). For given physical parameters, the temperature difference and the operating temperature were identified as the key operating variables. Zuo and Faghri [49] presented a network thermodynamic analysis where the transient heat pipe behavior was described by first-order, linear ordinary differential equations. The heat pipe was cast as a thermal network of various components, and analyzed in terms of a properties group and a dimensions group. A dimensionless number was proposed to evaluate the thermal compatibility of the dimensions with the materials used as follows:

$$
\Psi=\frac{\Phi}{\Theta} \geq 1
$$


in which $\Phi=\frac{\delta}{D} \frac{R_{v}{ }^{4}}{L_{c}\left(L_{e}+2 L_{a}+L_{c}\right)} \quad$ and $\quad \Theta=2 \mathrm{k}_{\mathrm{eff}} \frac{\mathrm{T}_{\mathrm{HP}} \mu_{\mathrm{v}}}{\rho_{\mathrm{v}}{ }^{2} \mathrm{~h}_{\mathrm{fg}}{ }^{2}}$.

A thermodynamic model of the vapor-liquid interface in micro heat pipes, including axial temperature and pressure differences, changes in the local interfacial curvature, disjoining pressure and Marangoni effects, was developed by Swanson and Peterson [50]. The vapor-liquid interface was subdivided in this model into three regions - the intrinsic meniscus, the transition region, and the thin film region - and treated separately.

Fundamental aspects of the fluid flow and heat transfer through liquid films in heat pipes, such as capillary flow, fluid friction, and an analysis of the meniscus, have been explored in several papers. Khrustalev and Faghri [51] proposed a mathematical model for heat transfer through thin liquid films in the evaporator section of heat pipes with capillary grooves. The heat conduction in the metallic fin between the grooves and the liquid film was modeled using an energy balance. The free surface temperature of the liquid film was determined using the extended Kelvin equation relating the vapor pressure over the thin evaporating film to the saturation pressure, while the interfacial resistance was obtained from kinetic theory. The film surface curvature was expressed in terms of solid surface curvature and film thickness. The heat flow in the liquid film was modeled in distinct regions: equilibrium film, micro film, transition and meniscus regions. In addition to distributions of the field variables, axial variations of the local heat flux and the heat transfer coefficient were obtained with respect to the roughness size and the input heat flux at the evaporator.

An augmented Laplace-Young equation was presented by Schonberg et al. [52] to describe the steady meniscus formed during high flux evaporation from a micro channel. Using a kinetic-theory model for interfacial heat flux, dimensionless temperature distributions were obtained. 
Pratt et al. [53] investigated thermocapillary effects in heated meniscii formed by volatile liquids in capillary-pumped heat transfer devices, and established a criterion for instability of the evaporating meniscus. An analysis based on conservation equations and stress balances was followed in this work by a stability analysis to obtain a critical wave number above which the system becomes unstable. The critical interfacial temperature difference, over a length scale defined as $x_{c}=\left(r h_{t r}\right)^{1 / 2}$, where $h_{t r}=[\bar{A} r /(2 \sigma)]^{1 / 3}$, was expressed as:

$$
\Delta \mathrm{T}_{\mathrm{c}}=\frac{2}{\mathrm{r}}\left(\frac{2 \overline{\mathrm{A}}^{\frac{1}{2}} \sigma}{\mathrm{r}}\right)^{\frac{2}{3}}
$$

Two different configurations of capillary-pumped phase change loops were experimentally investigated to examine the stability of a heated, evaporating meniscus within a porous medium and to understand the effect of instabilities. Good agreement was obtained between the theoretical predictions of the critical interfacial temperature gradient and the experimental data at the onset of instability.

Heat transfer characteristics of evaporating thin liquid films in V-shaped micro grooves with non-uniform imposed heat flux were analyzed by Ha and Peterson [54]. Combined liquid conduction and interfacial vaporization were used to describe the local interfacial mass flux, based on which a local heat transfer coefficient was defined. An expression was developed for the evaporating film profile. Ha and Peterson [55] further investigated the axial flow of an evaporating thin film through a $\mathrm{V}$-shaped micro channel, taking into account a gravity term to incorporate the effect of small tilt angles. Solutions to the resulting nonlinear governing equations were obtained using a perturbation method. 
Experiments were conducted by Ma et al. [56] to determine the influence of the air flow on the friction factor in counter-current flow of water and air through triangular channels. The dependence of the product of liquid friction factor and Reynolds number on the air velocity was obtained for different channel angles, and was found to increase with the air flow Reynolds number. The influence was found to be more predominant in grooves with larger channel angles as shown in Figure 16. A mathematical model for the friction factor for flow in triangular grooves was developed by Peterson and Ma [57]. The model considered interfacial shear stresses due to liquid-vapor frictional interactions in counter-current flow, and thus is particularly applicable in cases where the liquid surface is strongly influenced by the vapor flow direction and velocity. An analytical approach and approximate algebraic model for the radius of curvature of the meniscus in capillary flow along a micro groove channel was presented by Peterson and Ha [58]. A nondimensional expression for the dry out location was developed as a function of a parameter which consisted of the Bond number, capillary number, and dimensionless groove geometry.

Peng et al. [59] studied the rewetting characteristics of capillary-induced liquid flow in circular channels with micro grooves on the inside surface. Results from experiments were applied in a transient theoretical model to determine the location of the rewetting front in the evaporator as a function of the applied heat flux. Ochterbeck et al. [60] developed a model to analyze the depriming/rewetting characteristics of external-artery heat pipe designs (featuring a separate arterial channel for liquid flow) subjected to externally induced accelerations. The model considered the effects of longitudinal accelerations, the repriming time after termination of acceleration, and the rewetting characteristics of the circumferential grooves. The analytical 
results were compared with results of space flight experiments and found to agree well with the microgravity test results.

The entrainment phenomenon in two-phase parallel flows was studied by Kim and Peterson [61], using wave instability theories. Theoretical criteria for entrainment were compared with experimental observations on air-water and steam-water systems, and a modified theoretical criterion was developed. The onset of entrainment was detected visually with a highspeed video camera. Various instability criteria were compared and their dependence on temperature was discussed. Variations in critical vapor velocity were presented with respect to the liquid film thickness, vapor temperature and viscosity number $\mathrm{N}_{\mathrm{vi}}$. Kihm et al. [62] experimentally investigated the parameters governing liquid entrainment caused by a high-speed air stream passing over a saturated screen mesh interface. They developed correlations for critical velocity for dry out and for droplet mean diameter. The critical Weber number for various models of entrainment was compared by Kim and Peterson [61, 63]. Capillary and boiling limits which affect entrainment were theoretically investigated and compared with experimental data from a copper heat pipe. The characteristics of the wave-induced, intermediate and shear-induced modes of entrainment, as well as the thermal detection of entrainment were discussed. Experimental results on the variation of the critical Weber number at the onset of entrainment with vapor temperature, and the dependence of the critical Weber number on the viscosity number for various mesh sizes were compared with theoretical predictions. A dimensionless correlation for the critical Weber number was developed based on the experimental data [63]:

$$
\mathrm{We}_{\mathrm{vc}}=10^{-1.163} \mathrm{~N}_{\mathrm{vi}}^{-0.744}\left(\frac{\lambda_{\mathrm{c}}}{\mathrm{d}_{1}}\right)^{-0.509}\left(\frac{\mathrm{D}_{\mathrm{h}}}{\mathrm{d}_{2}}\right)^{0.276}
$$


Imura et al. [64] proposed a geometric model for the effective pore radius of screen wicks based on observation of the screen geometry through a microscope. Effective pore radii were calculated using this model and compared to those calculated from experimental data on the capillary height. The effects of surface treatment on the radius of curvature of the meniscus at the liquid-vapor interface were also studied. The experiments in this work were performed with water, ethyl alcohol and R-113. McCreery [65] investigated the liquid flow and vapor formation phenomena in a flat heat pipe with a two-dimensional heat pipe apparatus. Experimental observations made with isopropyl alcohol as the working fluid were used to explain the nature of the liquid-vapor interface, the vapor formation mechanism and the oscillatory mode of operation.

\section{HEAT PIPE START-UP FROM THE FROZEN STATE}

The transient problem of heat pipe start-up from the frozen state has been addressed in the literature. Jang et al. [66] studied a cylindrical heat pipe, considering conduction in the wall and wick (neglecting liquid-flow effects) and employing a one-dimensional model for vapor flow. An equivalent heat capacity method was used to model phase change in the working fluid during the start-up period. The effect of the boundary condition imposed on the outer wall on the start-up from a frozen state was studied in terms of time-dependent temperature distributions at the wall and the liquid-vapor interface, and axial variations of the vapor temperature, pressure, density and Mach number.

The freeze-thaw characteristics of a copper-water heat pipe were studied experimentally by Ochterbeck and Peterson [67]. The freezing and restart characteristics corresponding to different initial working fluid distributions were discussed. The effect of variations in the amount of noncondensible gas present in the working fluid was also studied experimentally. The 
freezing blow-by phenomenon during start-up was considered in a subsequent experimental investigation [68]. This phenomenon occurs when frozen working fluid which blocks vapor and liquid flow is melted, producing a pressure difference between the evaporator and condenser regions. Upon break-through of the blockage, liquid may be driven from the evaporator into the condenser, resulting in a sudden depletion of liquid in the wick in the evaporator and subsequent dry out. The depressurization caused after break-through of the blockage was found to lead to an increase in the heat transport rate beyond the existing evaporator power input, leading to dry out in the evaporator. A theoretical analysis was also presented to calculate the evaporating mass flow rate during the blow-by phenomenon.

A free-molecular, transition and continuum vapor flow model based on the dusty gas model was developed by Tournier and El-Genk [69] as an extension of their transient twodimensional model previously discussed [9], to analyze the start-up of a liquid metal heat pipe from the frozen state. The start-up was simulated by incorporating a two-dimensional freeze and thaw model which employed a volume-averaged homogeneous enthalpy method to predict the melt progression during start-up. The computed wall temperature during the transient period was found to be in good agreement with measurements on a radiatively cooled sodium heat pipe [70]. The freeze and thaw model was verified by comparing with analytical solutions for onedimensional conduction and two-dimensional freezing in a corner, with good agreement.

Faghri [71] analyzed the time-dependent wall and vapor temperature variations of a low temperature copper-water heat pipe during start-up from a frozen state and freeze-out from the normal operating conditions. Wall-temperature predictions from a two-dimensional numerical model were used to identify the failure of start-up; experimental results for startup failure were in excellent agreement with the predictions. A method of starting up a frozen heat pipe using a 
pulsed heat input was also discussed. Cao and Faghri [72] proposed a 'flat-front model' for the start-up process of a high temperature heat pipe, which treated the transient propagation of the axial wall temperature distribution as a moving hot zone with a steep front. Approximate closedform solutions for the transient temperature distribution in the hot zone as well as its length were found to agree well with experimental data for stainless steel-sodium systems [70, 73, 74]. A heat pipe limitation related to start-up was identified; the criterion proposed for start-up from frozen conditions without dry out occurring in the evaporator, was

$$
\frac{\varphi \rho_{1} \mathrm{~A}_{\mathrm{w}} \mathrm{h}_{\mathrm{fg}}}{\mathrm{C}\left(\mathrm{T}_{\mathrm{m}}-\mathrm{T}_{\mathrm{a}}\right)} \geq 1
$$

A more detailed simulation of the early start-up transient in a liquid metal (sodium) heat pipe from the frozen state by Cao and Faghri [75] considered five distinct periods within the start-up process. A rarefied gas flow self-diffusion model was proposed for the early start-up period, when rarefied flow is dominant. Separate solutions to the wall, wick and vapor regions were formulated, and coupled via interface mass fluxes. Predictions were compared with experimental measurements of the outer wall temperature [70, 73] with generally good agreement. The analysis revealed the existence of large vapor density gradients along the heat pipe at start-up. The criterion for the establishment of continuum flow, which delineated the early start-up period from the subsequent periods, was based on the Knudsen number (continuum for $\mathrm{Kn}<0.01)$. In further work, Cao and Faghri [76] coupled a continuum vapor flow model for a transient, compressible, laminar vapor flow analysis with the rarefied vapor self-diffusion model in a 'two region model' to describe the co-existence of continuum and rarefied vapor flow for most of the start-up period. The outside wall temperature from the numerical computation compared well with experimental data from various sources. It was concluded that the high temperature heat pipe start-up process was characterized by a moving hot zone with relatively 
steep fronts; in this moving hot zone, the temperature front in the vapor was steeper than in the wall, as shown for a typical case in Figure 17.

Jang [77] studied the start-up of liquid metal heat pipes. The transition temperatures during the change from a free-molecular flow to a continuum flow for these heat pipes were determined for different vapor space diameters. A potassium heat pipe was tested in a vacuum chamber and the surface temperature was compared with theoretically calculated values of the transition temperatures, which showed that the heat pipe was inactive until it reached the transition temperature, thus validating the prediction.

Ponnappan and Chang [42] experimentally studied the start-up performance of a liquid metal heat pipe in near-vacuum and gas-loaded conditions. A sodium heat pipe with an arterial wick was tested; argon gas was used for loading in the gas-filled mode, as discussed in II.B. In the vacuum mode, large temperature spikes were observed at the evaporator during the frozen start-up. In comparison, start-up was found to be smoother in the gas-filled mode.

Analysis of heat pipe start-up from the frozen state is important due to the existence of large thermal gradients and associated thermal stresses during the start-up period, and the possibility of dry out following the break down of the blockage, described as the blow-by phenomenon. As seen from the discussion in this section, the transient problem of heat pipe start-up from the frozen state has been analyzed, mostly in the case of conventional cylindrical designs. Analysis of frozen start-up in a variety of nonconventional heat pipes, however, has yet to be undertaken. 


\section{DISCRETE HEAT SOURCES AT THE EVAPORATOR}

In place of a uniformly distributed heat input at the evaporator, multiple discrete heat sources may be present. Such a situation has been analyzed as a conjugate heat transfer problem in a single domain, with a generalized energy conservation equation applicable in all regions of the heat pipe (Faghri and Buchko [78]). Laminar, subsonic, steady flow in low-temperature cylindrical heat pipes with multiple heat sources was considered. In the core, the ideal gas law was used to account for vapor compressibility. The wick was treated as an isotropic porous medium saturated with liquid, with the velocities being volume-averaged. The single-domain approach used in this work incorporated a source term in the momentum equation for the wick to account for porosity, as well as modified density and pressure variables for different regions of the heat pipe. Latent heat was added as a source term in the energy equation at the interface. The results included temperature distributions in the heat pipe wall and vapor, with different evaporator sections operating at different input levels. It was concluded that the heat transport capacity of the heat pipe could be increased by an optimized redistribution of the heat load. Numerical results were compared with results from experiments on a copper-water system with multiple heat sources, with excellent agreement.

Faghri et al. [70, 73] conducted transient experiments on a sodium-stainless steel heat pipe with multiple heat sources and sinks. Behavior during start-up from a frozen state was investigated under various heat loads and input locations, with different heat rejection rates at the condenser. Numerical simulations for the transient heat pipe performance were compared with experimental results. Through experiments conducted in a vacuum environment, the effect of surface emissivity on the steady-state axial distribution of vapor temperature was studied. The effect of start-up pressure on the temperature distribution was also explored. An interesting 
observation from this work was that the annular gap between the wick and the heat pipe wall and between adjacent layers of the wick generally enhanced the maximum heat transport capacity of the heat pipe.

Schmalhofer and Faghri [79, 80] experimentally and theoretically investigated a low temperature copper-water heat pipe under uniform circumferential heating, as well as block heating over either the upper or the lower half of the evaporator surface (with the heat pipe held horizontal). Transient wall and vapor temperatures were measured under various step heat input rates. Under similar conditions, the uniform and block-heating modes were found to exhibit almost equal times to undergo a given temperature rise. Numerical and experimental results of the variation of the capillary limit with vapor temperature were also obtained. Temperature profiles and velocity maps were predicted (as shown in Figures 18 and 19 respectively) and were found to agree well with experimental results. The experimental values for the capillary limit were found to agree with the theoretical predictions to within $\pm 25 \%$.

\section{HEAT PIPE APPLICATIONS}

Studies of heat pipes in the literature have been directed at a number of diverse applications, some of which have been discussed in the foregoing. For instance, the application considered by Vafai and Wang [17] was the cooling of a lithium target used in neutron production and in moderating the production of neutrons, for the treatment of brain tumors. Additional examples of application-oriented investigations are covered in this section.

The technical feasibility of applying heat pipes in the extraction of heat from the ground in volcanic zones was explored by Tanaka et al. [81]. A network analysis was used to obtain the temperature distribution in the heat pipe and the surrounding earth; the results were also 
compared to experimental data. McGuinness [82] analyzed heat pipes for geothermal applications and obtained steady-state solutions; maximum possible lengths of heat pipes were calculated for geothermal applications.

Modifications to heat pipes for application in spacecraft thermal control systems were investigated by Schlitt [83]. The use of composite wick designs with large liquid cross sections, and designs with circumferential grooves in the evaporator to handle high heat loads was investigated. Configurations with liquid fillets and axially tapered liquid channels were proposed for improving the performance of composite wicks. The design, development and testing of a pumped heat pipe cold plate for high heat flux space applications was reported by Ambrose et al. [84]. This heat pipe was designed to integrate detachable spacecraft payloads to a pumped thermal control loop, using ammonia as the working fluid. Experimental studies were conducted on stainless steel-potassium heat pipes under space flight and ground test conditions by Dickinson et al. [85], to characterize the start-up behavior, compare in-flight and ground performance under start-up, operation and shut down conditions, and assess the design in terms of the measured energy throughput and evaporator temperatures as well as calculated thermal resistances.

Wei et al. [86] performed experimental and analytical studies on a planar heat pipe used as a cooling fin in the dissipation of high heat fluxes. The configuration used consisted of a main fin (a vertically oriented plate) with heat pipes used as sub-fins protruding horizontally from the main fin. A simple two-dimensional model was used assuming a uniform saturated temperature and pressure for the vapor and liquid; the axial wall temperature gradient was neglected. Correlations were used to represent the convective heat transfer coefficients outside, as well as the evaporation and condensation inside the heat pipe. The experimental and calculated 
temperature variations were compared for charged and uncharged heat pipes, as shown in Figure 20. Zhao and Avedisian [87] compared the heat dissipation due to an array of copper plate fins mounted on a cylindrical copper heat pipe, with an identical array mounted on a solid copper rod. The heat pipe used a sintered copper wick and water as the working fluid. The main parameter investigated was the module height. It was found that under forced convection, fins supported by the heat pipe dissipated heat transfer rates that were higher by as much as three times compared to fin arrays supported by the copper rod, under identical conditions. This improvement in heat transfer rate decreased as the height of the fin stack decreased.

\section{MICRO HEAT PIPES}

An important class of nonconventional heat pipes is the micro heat pipe. A micro heat pipe essentially consists of micro channels of polygonal cross section. While vapor flows through the interior of the micro channels, liquid flows back by capillary action along the corners of the channels. Micro heat pipes do not require a wick for liquid flow. They are especially promising in cooling microelectronic devices due to their small size and high thermal conductance.

The literature on miniature and micro heat pipes was reviewed by Cao et al. [88]. The capillary limit for micro heat pipes was analyzed, and the existence of a 'vapor continuum limitation' for micro heat pipes was discussed, in addition to the other limits for conventional heat pipes.

Theoretical modeling of micro heat pipes in the literature has been based on a solution of the conservation equations for fluid flow in the micro channels. Problems associated with the modeling have included the incorporation of frictional effects and the variation in meniscus 
radius along the flow direction. Experimental studies, on the other hand, have been mostly confined to external temperature measurements and determination of heat transport limits.

One of the more widely cited studies on modeling and testing of micro heat pipes was performed by Babin et al. [89]. This paper discussed the fundamental concepts of micro heat pipes and presented combined experimental and analytical investigations to understand the phenomena that govern the performance limitations and operating characteristics of the micro heat pipe. A micro heat pipe made of copper or silver with a single channel of trapezoidal cross section was studied with water as the working fluid. An expression for the capillary limit was derived and the limits of operation computed. The variation of pressure and the dependence of heat transfer limits on the operating temperature and tilt angle were presented. Experiments were conducted in the charged and uncharged states, under vacuum as well as under cooling at the condenser. Variations of thermal conductance (as shown in Figure 21), input power and temperature distribution with changes in the evaporator temperature were measured under steady-state operation. A transient numerical model was developed by Wu and Peterson [90] to analyze this heat pipe. Expressions for free molecular flow mass flux of evaporation and condensation [91] were employed, along with the Laplace-Young equation for the variation of meniscus radius. An important observation from this work was a reversal of liquid flow during the early transient period, explained as being due to a pressure imbalance. It was also concluded that the wetting angle was one of the most important factors contributing to the transport capacity of micro heat pipes. The numerical model was found to predict accurately the steadystate experimental results of [89]. Transient measurements of the wall temperature and the maximum transport capacity in tapered micro heat pipes were reported by $\mathrm{Wu}$ et al. [92], who tested charged and uncharged silver heat pipes at a constant condenser temperature. The 
numerical model was found to predict the steady-state results well, but underestimated the transient response.

Micro heat pipes fabricated as an integral part of silicon wafers have also been studied, since the problems with thermal contact resistance between the heat pipe and device can be circumvented by this means, leading to very effective heat removal. Peterson et al. [93] compared temperature variations in a silicon wafer with and without micro heat pipe grooves. At a power level of $4 \mathrm{~W} / \mathrm{cm}^{2}$, the wafer with the integral heat pipe showed a reduction in maximum chip temperature of as much as $11^{\circ} \mathrm{C}$, as well as an increase in effective thermal conductivity by up to $25 \%$, compared to the ungrooved wafer. Some of the details of fabrication and charging were discussed. Peterson [94] further discussed various aspects of the fabrication, operation, modeling and testing of integral micro heat pipes in silicon. More extensive work on similar micro heat pipes with triangular and rectangular grooves was reported in Peterson et al. [95]. Figure 22 shows a comparison of the maximum temperature and effective thermal conductivity of wafers with and without micro heat pipe arrays obtained in this work, and illustrates the improvement in performance due to the micro heat pipe array. A discussion of the use of micro heat pipes as an integral part of semiconductor devices was also presented by Mallik et al. [96].

Parametric studies on a micro heat pipe array fabricated in silicon using vapor deposition were performed by Mallik and Peterson [97], with the number of heat pipes in the array and the heat input as parameters. The maximum heat transport capability of the micro heat pipe was found to vary inversely with its length and as the cube of its hydraulic diameter. This work was extended to include transient performance by Peterson and Mallik [98]. An analytical model was developed by Duncan and Peterson [99] for a triangular, etched micro heat pipe, with predictive 
capabilities for the capillary limit of operation, the curvature of the meniscus in the evaporator and the optimal value of the liquid charge.

The maximum heat transfer capabilities of flat copper-water micro heat pipes were explored by Hopkins et al. [100]. The maximum heat load for various operating temperatures was determined experimentally, in trapezoidal and rectangular micro grooves in vertical and horizontal orientations, as was the dry out condition. The experimental results showed that the effective thermal resistance decreased with an increase in heat transport, as shown in Figure 23. A one-dimensional model describing the fluid flow in a miniature grooved heat pipe was used to predict the capillary limitation on heat transport. The analysis employed two different regions based on the liquid-vapor meniscus behavior: one at the beginning of the evaporator where the contact angle was constant, and a second in the adiabatic and condenser sections where the contact angle varied along the axis.

A detailed mathematical model for the analysis of a micro heat pipe, which described the liquid distribution and thermal characteristics in relation to the liquid charge and heat load, was developed by Khrustalev and Faghri [101]. The variation in curvature of the free liquid surface as well as the interfacial shear stress due to liquid-vapor frictional interaction were represented in the model. Correlations from the literature were utilized for friction, while heat transfer in the condenser and evaporator were incorporated through mean heat transfer coefficients estimated analytically. The importance of the liquid fill, contact angle and the interfacial shear stress in predicting the maximum heat transfer capacity and the thermal resistance was demonstrated. The liquid cross-sectional area, and the meniscus curvature and contact angle were obtained. The predicted results were compared to existing experimental data [90] for copper-water and silver-water systems. Good agreement was obtained between the experimental results and 
numerical predictions for the onset of dryout. A new flat micro heat pipe configuration with an increased liquid cross-sectional area was proposed for electronics cooling applications.

Longtin et al. [102] presented a steady-state, one-dimensional model of the evaporator and adiabatic sections of a micro heat pipe with triangular channels, incorporating local variations in the channel cross-sectional area through geometric coefficients. The formulation assumed a nearly isothermal device with the vapor temperature being almost constant; the energy equation was solved in the liquid phase. The Laplace-Young equation was used at the meniscus. The conservation equation for mass included an influx term for evaporation, and the interfacial velocity was incorporated through an energy balance at the interface. A comparison of the predicted results from this model with heat transfer rate data from copper-water and silver-water systems [89] is shown in Figure 24.

A transient theoretical analysis of one-dimensional vapor and liquid flow in a micro heat pipe of triangular cross section was performed by Sobhan et al. [103]. A micro heat pipe with evaporator and condenser sections was analyzed. The formulation solved the energy equation in the vapor as well as the liquid. The resulting vapor temperature distributions provided a means for calculating the overall effective thermal conductivity of the heat pipe. Variations of the instantaneous effective thermal conductivity and the steady-state effective thermal conductivity with respect to heat input were obtained as shown in Figure 25.

Peterson and Ma [104] proposed a model for predicting the minimum meniscus radius and the maximum heat transport in triangular grooves. A hydraulic diameter incorporating the effect of frictional liquid-vapor interactions was defined and used in the modeling. The results indicated that the heat transport capacity of the micro heat pipe depended strongly on the apex channel angle of the liquid arteries, contact angle of liquid flow, length of the heat pipe, vapor 
flow velocity, and the tilt angle. Analytical expressions for the minimum meniscus radius and maximum capillary heat transport limit in micro heat pipes were presented by Ma and Peterson [105]. Comparisons with experimental data from triangular grooves and micro heat pipes were made for the maximum capillary heat transport predicted, which indicated that the analytical expressions can be used to predict the maximum capillary heat transport with a high degree of accuracy.

Ma and Peterson [106] conducted experiments to measure the capillary heat transport limit and a 'unit effective area heat transport,' defined for small triangular grooves as $\mathrm{Q}_{\mathrm{eff}}=$ $\mathrm{Q} / \mathrm{A}_{\text {eff }}$, where $\mathrm{A}_{\text {eff }}=\mathrm{D}_{\text {eff }} \mathrm{L}_{\mathrm{e}}$. Methanol was the working fluid in grooved copper. It was found that there was an optimum geometry for which the unit effective area heat transport was a maximum, and that this maximum depended on the tilt angle and the effective length of the heat pipe.

A semi-empirical correlation was developed by Ha and Peterson [107] for predicting the maximum heat transfer capacity in micro heat pipes. This was achieved by modifying the analytical model for the maximum heat capacity developed by Cotter [108] to obtain better agreement between the experimental and predicted results. The modified model incorporated the effects of the temporal intrusion of the evaporator section into the adiabatic section of the heat pipe occurring near dry out.

Visualization experiments were conducted by Chen et al. [109] with glass micro heat pipes fabricated by attaching a wire insert to the inner wall of a glass capillary tube. The heat pipe was also modeled as a porous medium experiencing two-phase flow. A comparison of the predicted and experimental values for maximum heat flow in the horizontal and vertical orientations revealed that the effect of gravity was significant. A number of other studies on 
micro heat pipes (for example, $[110,111]$ ) have considered the effect of system parameters such as tilt angle, condenser side heat removal and quantity of charge on the maximum heat transport limits.

\section{THERMOSYPHONS}

Two-phase thermosyphons, or 'wickless heat pipes,' utilize the counter-current flow of the liquid and vapor phases for heat transfer. The essential difference between a heat pipe and a thermosyphon is that the latter does not use a wick structure for the return of the condensed fluid to the heated region, but instead achieves this by gravity or by mechanical means. A closed twophase thermosyphon consists of a liquid pool contained in the heated section or evaporator, an adiabatic section and a cooled or condenser section. Conventional and miniature forms of thermosyphons have been developed for use as heat exchangers in applications ranging from energy conversion systems to electronics cooling. Studies of thermosyphons, both theoretical and experimental, have explored the operational limits, as well as the effects of important parameters such as the nature and filling ratio of the working fluid, tilt angle and geometric dimensions on the maximum heat transport. Several nonconventional shapes and special applications have also been investigated.

Bezrodny and Podgoretskii [112] studied the flooding and heat transfer limits in twophase thermosyphons. The effect of inclination angle, filling ratio, pressure and the working fluid on the limiting axial flux were studied. An optimum filling ratio was obtained as a function of the inclination angle.

The flooding limit in a closed two-phase thermosyphon was determined by Shatto et al. [113] by monitoring the thermal resistance for different fluids with high fill ratio. Visual 
observations revealed that the transition from annular to churn flow took place well below the flooding limit.

Numerical modeling of a closed two-phase thermosyphon under steady-state operation was performed by Zuo and Gunnerson [114]. The effect of the axial normal stress in the liquid film was considered in the analysis, in addition to the interfacial shear. Harley and Faghri [115] modeled the operation of a thermosyphon under transient conditions by treating the falling condensate film using a quasi-steady state Nusselt-type analysis. The effects of vapor compressibility and conjugate heat transfer at high temperatures were examined. The numerical predictions were compared with experiments and good agreement was observed at low temperatures.

El-Genk and Saber [116] proposed correlations to calculate the expanded (due to the vapor voids inside the liquid pool) liquid pool height in the evaporator of a closed thermosyphon based on numerical modeling. An interfacial shear stress analysis was used to determine the liquid film thickness in the evaporator, immediately above the expanded boiling pool. The calculated liquid pool heights were compared to experimentally determined values for acetone, ethanol and water, and found to agree within $\pm 8 \%$. The influence of the lengths of the adiabatic and condenser sections on the operation of the thermosyphon as obtained in this study are shown in Figure 26.

Inclined two-phase thermosyphons have been analyzed in numerical and experimental studies. Zuo and Gunnerson [117] developed a model which could predict the occurrence of dry out when the liquid film thickness or axial liquid film velocity became zero at any location on the evaporator wall. The mean and maximum heat transfer rates, the minimum evaporator charging ratio, the liquid-vapor interfacial shear stresses, and the effects of working fluid 
inventory were all studied as a function of inclination angle. Visual observations of the effect of inclination angle on the flow patterns in an inclined thermosyphon were reported by Shiraishi et al. [118]. Flow phenomena were recorded and the corresponding heat transfer rates measured. The flow patterns were classified into annular and stratified flow regimes. In the case of stratified flow, it was found that dry out occurred due to the depletion of the working fluid from the evaporator section following the development of an interfacial liquid wave.

Peterson et al. [119] discussed flow instability and bifurcation in gas-loaded thermosyphons, utilizing the Clausius-Clapeyron equation at the liquid-vapor interface and Dalton's law for determining the gas concentration. Experimental results were also presented showing the variations in the gas flow pattern as the Rayleigh number was increased. Zhou and Collins [120] carried out theoretical and experimental studies on condensation in a cylindrical, two-phase thermosyphon containing a noncondensible gas.

The application of a two-phase thermosyphon in cooling high power multichip modules in a switching system for broad band ISDN was discussed by Kishimoto and Harada [121]. The cold-plate temperatures were experimentally mapped, and the influence of tilt angle on the thermal resistance studied.

The heat flux density, vapor temperature and overall heat transfer coefficient for a twophase, right-angled elbow thermosyphon were obtained by Lock and Fu [122]. A horizontal orientation for the evaporator and condenser was found to lead to a hold up in the condenser coupled with dry out, which could stop the thermosyphon operation. Experimental studies on a two phase thermosyphon with a "cranked" configuration (where the evaporator and condenser sections are offset from each other) was also reported by Lock and Fu [123]. Experiments with distilled water as the working fluid revealed that the heat transfer rates were much higher than 
those obtained for single phase thermosyphons [124] and also that the critical heat fluxes were lower than those in a linear (not offset or "cranked") system [125].

Lin et al. [126] considered a thermosyphon with a built-in cross-over flow separator. The cross-over flow separator helps to collect the condensate flow and route it to the liquid pool through a feed tube, thus avoiding flooding that could be caused when the liquid film flows down the heated wall. The analysis incorporated an empirical correlation for wall friction; water, ethanol, Freon 11 and Freon 113 were the working fluids studied. Expressions were derived for the critical heat flux resulting from a flow instability. The calculated maximum heat transfer was compared with experimental data and was found to agree within $\pm 15 \%$.

Islam et al. [127] conducted experiments on an open concentric-tube thermosyphon to understand the effects of the geometric parameters (tube diameter and heated length) on the critical heat flux. The existence of an optimum diameter for the inner tube, for which the critical heat flux was a maximum, was demonstrated for a given diameter of the heated outer tube and working fluid.

\section{CAPILLARY PUMPED LOOPS}

The capillary pumped loop (CPL), like the heat pipe, is a two-phase heat transfer device which operates with no external pumping power. The CPL utilizes the surface tension forces developed in a wick locally positioned in the evaporator zone to circulate the working fluid. Capillary pumped loops encounter lower wick pressure losses compared to heat pipes. In the CPL, the liquid and vapor flows are confined to separate sections of the loop, unlike the countercurrent flow in heat pipes. Theoretical models and experimental studies on capillary pumped loops in the recent literature are briefly discussed in this section. 
A review of the developments in capillary pumped loop technology since the late 1970s was presented by $\mathrm{Ku}$ [128]. A discussion of CPL designs aimed at enhancing overall system performance was presented. The design of high-temperature CPLs operating between 975 and $1075 \mathrm{~K}$, with sodium as the working fluid, was described by Anderson [129]. These CPLs were capable of transferring $5300 \mathrm{~W}$ with a peak evaporator heat flux of $67.5 \mathrm{~W} / \mathrm{cm}^{2}$.

A conjugate analysis of a flat plate evaporator for CPLs with three-dimensional vapor flow was presented by Cao and Faghri [130]. The model analyzed flow and heat transfer in the porous wick, vapor flow in the grooves and heat transfer in the cover plate, with the liquid and vapor flows being coupled through the interfacial mass flux. Water, Freon-11 and ammonia were used as the working fluids. In comparison with the three-dimensional model, it was found that relatively accurate results could be obtained using a two-dimensional model in the cases of Freon-11 and ammonia.

Experimental and analytical studies of a CPL at various power inputs and adverse tilts were presented by Dickey and Peterson [131]. The model showed good agreement with experimental results, and indicated that the overall heat transport capacity of the CPL was significantly higher than that expected in conventional heat pipes. For small values of power input, the effective thermal resistance of the CPL was found to decrease drastically with increasing power input, as shown in Figure 27.

Muraoka et al. [132] investigated a CPL with the conventional tube condenser replaced with one having a porous element inside. A mathematical model for this CPL was presented and experimentally validated. Boo and Chun [133] conducted experiments on a copper-ethanol CPL to study the thermal performance of a flat evaporator. Layers of coarse-screen wicks were utilized at the evaporator to provide irregular passages for vapor flow. The thermal resistance of 
the system was calculated as a function of the heat flux and condenser cooling rate. Bazzo et al. [134] presented a mathematical model to predict the hydrodynamic behavior and heat transport capability of a Freon-11 CPL. The start-up behavior, heat transport limits and repriming after dry-out were investigated. The model predictions were found to agree well with experiments.

Krotiuk [135 reported on the testing of a CPL thermal control system for the NASA EOS-AM spacecraft. Tests were performed at ambient conditions and under vacuum, with ammonia as the working fluid. Bugby et al. [136] presented experimental results for start-up from a supercritical state and operation under adverse evaporator elevation for a cryogenic CPL using neon as the working fluid.

\section{INVENTIONS AND PATENTS}

A number of inventions based on new principles, designs and applications of heat pipes have been reported in the recent past. While some of these deal with an improvement in the design of existing heat pipes and enhancement of their performance, most concentrate on the application of heat pipes to diverse fields. A search of the patents involving heat pipes awarded in the past decade was performed as part of this review, and results of the 159 US patents collected are summarized in this section as evidence of the active and continued interest in heat pipe development.

The largest single category of patents, a total of 34, were related to electronics cooling. Twenty-eight inventions incorporated new designs in terms of principles, configurations, and shapes. Twenty-six patents were issued for new materials and methods in heat pipe manufacture. Applications of heat pipes to heat exchangers were the focus of 16 patents, while 11 dealt with space conditioning and refrigeration devices. Twelve others consisted of accessories and 
auxiliary equipment for heat pipe systems. Among the other major inventions, six dealt with the enhancement of heat pipe performance, and four offered heat pipe-based equipment for use in biomedical and human comfort applications.

In addition to the patents in the above categories, there were 22 additional inventions related to the use of heat pipes in equipment for specific and diverse applications including: vacuum processing chambers, vapor deposition systems, crystal growth apparatus, heat dissipating devices in spacecraft, cooling of electrical machines, thermal switches, ovens, microwave heating systems, thermal storage systems, cooling of enclosures, cryogenic heat transfer, cooling of laser heads, image-forming apparatus such as copiers and printers, inkjet apparatus, structural panels, asphalt road construction, roller with temperature sensors for photographic film development, metallurgy (reclaiming vaporized metals from smoke stacks), electromagnetic coupling apparatus and hair styling.

\section{CLOSURE}

As seen from the discussion presented, research in heat pipes over the past decade may be grouped into several different thrust areas. One such area of focus has involved modeling of the transport processes in heat pipes to obtain the spatial and temporal distributions of the field variables. In general, the appropriate forms of the conservation equations have been solved in different regions, treating each region of the heat pipe individually, or using a single-domain approach. One of the more common simplifying assumptions has been to consider only conduction in the liquid-saturated wick, using appropriate models for thermal conductivity and diffusivity. In a number of studies, the wick has been modeled as a porous medium using Darcy's law. Only a few investigations have solved the complete set of transport equations in 
the wick. It is important that realistic models of heat pipe behavior include a detailed analysis of the flow and heat transport through the wick. Although some attempts at representing the transport problem in nondimensional terms have been reported, a general physics-based approach to the nondimensionalization scheme needs further attention.

Prediction of the various operating limits (capillary, boiling, entrainment) on heat transport in heat pipes has been another focus area of research. Theoretical predictions, visual observations and temperature measurements have been used in identifying or verifying the predicted limiting conditions, both for the nonconventional designs discussed in this review, and for micro heat pipes.

A third area of research has investigated specific designs of nonconventional heat pipes suited to particular applications, including special shapes (disk-shaped, annular core), geometries (helical grooves), and modes of operation (reciprocating, rotating, pumped liquid return). Novel approaches, such as application of an electric field to enhance the liquid flow, have also been explored. A majority of the results in this area have been obtained from numerical modeling.

Apart from these three broad categories of research, investigations into fundamental thermodynamic and fluid mechanics considerations in heat pipes have been reported. These include discussions of meniscus formation, liquid film behavior and microchannel flow.

Miniaturization of heat pipes is a topic of great current interest and practical utility in the context of electronics cooling, and is the focus of ongoing work in the authors' group. While micro heat pipes have received much attention, less is known about scaling down wicked heat pipes to miniature size. The appropriate scaling methodology to arrive at smaller dimensions while still dissipating practically useful levels of heat presents an interesting area for further research. The operating limits of these miniaturized heat pipes need to be explored, as does a 
quantification of the dynamic pressure drop and the pressure recovery in the condenser for such heat pipes. Other approaches to miniaturization could include the reduction of the overall length of the heat pipe by employing internal surface enhancement at the evaporator and condenser sections.

Another topic that requires attention is the operation of heat pipes under partial load. A knowledge of the variation of the performance of the heat pipe operating at steady state but not under full heat load would find use in heat pipe applications. There is also a need for detailed local and transient measurements obtained through experimental studies; novel techniques could be used to carry out measurements inside the heat pipe such as for velocities and vapor temperatures. This would provide a database against which results from numerical programs may be benchmarked.

\section{Acknowledgement}

Support for this work was provided by members of the Purdue Cooling Technologies Research Consortium (http://widget.ecn.purdue.edu/ CTRC) directed by SVG, and is gratefully acknowledged. 


\section{Nomenclature}

A Hamaker constant (J)

$\overline{\mathrm{A}}$ Modified Hamaker constant (J) in Equation (3), [A/6 $\pi]$

$\mathrm{A}_{\mathrm{w}} \quad$ Cross-sectional area of working fluid in the wick $\left(\mathrm{m}^{2}\right)$

$\mathrm{A}_{\mathrm{eff}}$ Effective cross-sectional area of the groove $\left(\mathrm{m}^{2}\right)$

$A_{h p} \quad$ Cross sectional area of the heat pipe $\left(\mathrm{m}^{2}\right)$

$a_{\mathrm{r}} \quad$ Radial acceleration vector $\left(\mathrm{m} / \mathrm{s}^{2}\right)$

C Heat capacity per unit length $(\mathrm{J} / \mathrm{K} \mathrm{m})$

CCFL Counter current flooding limit

D Diameter (m)

$\mathrm{D}_{\text {eff }} \quad$ Hydraulic diameter $(\mathrm{m})$

$\mathrm{D}_{\mathrm{h}} \quad$ Duct hydraulic diameter $(\mathrm{m})$

$\mathrm{D}_{\mathrm{r}} \quad$ Liquid loading, $\left[\mathrm{H} / \mathrm{R}_{\mathrm{o}}\right]$

$\mathrm{d}_{1} \quad$ Wire spacing (m) in Equation (4)

$\mathrm{d}_{\mathrm{i}} \quad$ Inner surface diameter in Figure 26

$\mathrm{d}_{2} \quad$ Wire thickness (m) in Equation (4)

Fr Froude number, $\left[\Omega^{2} \mathrm{R}_{\mathrm{o}} / \mathrm{g}\right]$

$F_{1} \quad$ Liquid friction factor

f Working frequency of heat pipe $\left(\mathrm{s}^{-1}\right)$

FMHP Flat miniature heat pipe

g Gravitational acceleration $\left(\mathrm{m} / \mathrm{s}^{2}\right)$

$\mathrm{H} \quad$ Average film thickness (m)

$\mathrm{h}_{\mathrm{fg}} \quad$ Latent heat of vaporization $(\mathrm{J} / \mathrm{kg})$ 
$\mathrm{h}_{\mathrm{tr}} \quad$ Transition film thickness (m)

$\mathrm{h}_{\mathrm{c}} \quad$ Condensation heat transfer coefficient $\left(\mathrm{W} / \mathrm{m}^{2} \mathrm{~K}\right)$

$\mathrm{h}_{\mathrm{v}} \quad$ Vapor phase thickness (m)

$\mathrm{I}_{\mathrm{m}} \quad$ Liquid impingement number, $\left[\mathrm{v}_{\mathrm{l}} \mathrm{L} /\left(\mathrm{r}_{\mathrm{c}} \mathrm{f} \mathrm{A}_{\mathrm{hp}}\right)\right]$

$\mathrm{k}_{\mathrm{eff}} \quad$ Effective thermal conductivity $(\mathrm{W} / \mathrm{mK})$

$\mathrm{k}^{*} \quad$ Effective thermal conductivity ratio, $\left[\mathrm{k}_{\mathrm{eff}} / \mathrm{k}_{\mathrm{copper}}\right]$

L Length of the heat pipe (m)

$\mathrm{L}_{\mathrm{a}} \quad$ Length of adiabatic section (m)

$\mathrm{L}_{\mathrm{c}} \quad$ Length of condenser section (m)

$\mathrm{L}_{\mathrm{e}} \quad$ Length of evaporator section (m)

$1_{e} \quad$ Length of the evaporating section of the grooved plate (m)

$1^{+} \quad$ Dimensionless length of the heat pipe

$\mathrm{N} \quad$ Rotational speed of the heat pipe (rpm)

$\mathrm{N}_{\mathrm{vi}} \quad$ Dimensionless viscosity number, $\left(\frac{\mu_{1}}{\sqrt{\rho_{1} \sigma \lambda_{\mathrm{c}} / 2 \pi}}\right)$

NZ Axial node number

n' Number of active sites per square centimeter for nucleate boiling

$\Delta \mathrm{P}_{1} \quad$ Overall liquid pressure drop along the length of the heat pipe (Pa)

$\Delta \mathrm{P}_{\mathrm{v}} \quad$ Overall vapor pressure drop along the length of the heat pipe (Pa)

$\mathrm{P}_{\mathrm{o}} \quad$ Initial pressure $\left(\mathrm{N} / \mathrm{m}^{2}\right)$

Pr Prandtl number

$\mathrm{P}_{\mathrm{x}} \quad$ Local pressure value $\left(\mathrm{N} / \mathrm{m}^{2}\right)$

Q Heat transfer rate (W) 
Q $\quad$ Unit effective area heat transport $\left(\mathrm{W} / \mathrm{m}^{2}\right)$

Q $\quad$ Input power (W)

$\mathrm{Q}_{\max }$ Maximum axial heat flow through the heat pipe cross section (W)

$\mathrm{R}_{\mathrm{o}} \quad$ Radius of tube $(\mathrm{m})$

$\mathrm{R}_{\mathrm{th}} \quad$ Thermal resistance $(\mathrm{K} / \mathrm{W})$

$\mathrm{R}_{\mathrm{V}} \quad$ Vapor core radius (m)

r Radius of curvature of the intrinsic meniscus (m) in Equation (3)

r Radial coordinate for the disk-shaped heat pipe (m) in Figure 10

$\mathrm{r}^{*} \quad$ Nondimensional radius

$r_{c} \quad$ Radius of the engine crank $(m)$

$\operatorname{Re}_{\text {ext }}$ Film Reynolds number at evaporator exit [4Q / $\left.\left(\pi d_{i} h_{f g} \mu_{1}\right)\right]$ in Figure 26

$\mathrm{Re}_{\mathrm{n}} \quad$ Injection Reynolds number

$\operatorname{Re}_{\mathrm{v}} \quad$ Vapor Reynolds number

$\mathrm{Re}_{\mathrm{h}, 1} \quad$ Liquid Reynolds number based on hydraulic diameter

T Temperature $(\mathrm{K})$

$\Delta \mathrm{T} \quad$ Temperature drop $(\mathrm{K})$

$\mathrm{T}_{\mathrm{a}} \quad$ Ambient temperature or initial temperature of the frozen heat pipe $(\mathrm{K})$

$\Delta \mathrm{T}_{\mathrm{c}} \quad$ Critical interfacial temperature difference $(\mathrm{K})$

$\mathrm{T}_{\mathrm{HP}} \quad$ Temperature of heat pipe $(\mathrm{K})$

$\mathrm{T}_{\mathrm{m}} \quad$ Melting temperature of the working substance in Equation (5)

$\mathrm{T}_{\mathrm{m}} \quad$ Mean working temperature of the heat pipe (K) in Figure 11

$\mathrm{T}_{\mathrm{V}} \quad$ Vapor temperature $(\mathrm{K})$

$\Delta \mathrm{T}_{\mathrm{w}} \quad$ Sum of wall temperature drops on the evaporator and condenser $\left({ }^{\circ} \mathrm{C}\right)$ 
$\mathrm{t} \quad$ Time (s)

U Longitudinal velocity $(\mathrm{m} / \mathrm{s})$

$\mathrm{V}^{+} \quad$ Fill ratio

$\mathrm{V}_{1} \quad$ Liquid volume in heat pipe $\left(\mathrm{m}^{3}\right)$

$\mathrm{V}_{\mathrm{hp}} \quad$ Heat pipe volume $\left(\mathrm{m}^{3}\right)$

$\mathrm{We}_{\mathrm{vc}}$ Critical Weber number

X Axial distance (mm)

$\mathrm{x}^{+} \quad$ Dimensionless axial length

$\mathrm{x}_{\mathrm{g}} \quad$ Mole fraction of the noncondensible gas

y Transverse coordinate in the flat heat pipe

$\mathrm{y}^{*} \quad$ Nondimensional transverse coordinate

z Axial coordinate (m)

$\mathrm{z}^{*} \quad$ Nondimensional axial coordinate

\section{Greek}

$\delta \quad$ Wick thickness (m)

$\varepsilon \quad$ Wick porosity

$\Phi \quad$ Geometric dimensions group $\left(\mathrm{m}^{2}\right)$ in Equation (2)

$\phi \quad$ Channel half-angle (degrees)

$\varphi \quad$ Heat pipe wick porosity in Equation (5)

$\varphi \quad$ Inclination angle from horizontal (deg) in Figure 6

$\lambda_{\mathrm{c}} \quad$ Critical wavelength (m)

$\mu_{1} \quad$ Liquid viscosity (Ns $\mathrm{m}^{-2}$ ) 
$\mu_{\mathrm{v}} \quad$ Vapor Viscosity $\left(\mathrm{Ns} \mathrm{m}^{-2}\right)$

$v_{1} \quad$ Kinematic viscosity of liquid $\left(\mathrm{m}^{2} / \mathrm{s}\right)$

$\Theta \quad$ Thermophysical properties group $\left(\mathrm{m}^{2}\right)$ in Equation (2)

$\rho_{\mathrm{v}} \quad$ Vapor density $\left(\mathrm{kg} / \mathrm{m}^{3}\right)$

$\rho_{1} \quad$ Density of the liquid $\left(\mathrm{kg} / \mathrm{m}^{3}\right)$

$\sigma \quad$ Surface tension $(\mathrm{N} / \mathrm{m})$

$\Omega \quad$ Angular velocity ( $\mathrm{rad} / \mathrm{s})$

$\Psi \quad$ Dimensionless number in Equation (2) 


\section{REFERENCES}

1. Jang, J. H., Faghri, A., and Chang, W. S., 1991, "Analysis of the One-Dimensional Transient Compressible Vapor Flow in Heat Pipes," International Journal of Heat and Mass Transfer, Vol. 34, pp. 2029-2037.

2. Bowman, W. J., 1987, "Simulated Heat Pipe Vapor Dynamics," Ph. D. Dissertation, Air Force Institute of Technology.

3. Ivanovskii, M. N., Sorokin, V. P., and Yagodkin, I. V., 1982, “The Physical Principles of Heat Pipes," Clarendon Press, Oxford.

4. Bowman, W. J., Winn, R. C., and Martin, H. L., 1992, "Transient Heat Pipe Modeling: A Quasi-Steady, Incompressible Vapor Flow Model," AIAA Journal of Thermophysics and Heat Transfer, Vol. 6, pp. 571-574.

5. Bowman, W. J. and Beran, P. S., 1994, "Implicit Heat Pipe Vapor Model," AIAA Journal of Thermophysics and Heat Transfer, Vol. 8, pp. 187-190.

6. Issacci, F., Catton, I., and Ghoniem, N. M., 1991, "Vapor Dynamics of Heat Pipe StartUp,” ASME Journal of Heat Transfer, Vol. 113, pp. 985-994.

7. Zuo, Z. J. and Faghri, A., 1997, "Boundary Element Approach to Transient Heat Pipe Analysis," Numerical Heat Transfer, Vol. 32A, pp. 205-220.

8. Cao., Y. and Faghri, A., 1990, "Transient Two-Dimensional Compressible Analysis for High-Temperature Heat Pipes with Pulsed Heat Input," Numerical Heat Transfer, Vol. 18, pp. $483-502$.

9. Tournier, J. M. and El-Genk, M. S., 1994, "A Heat Pipe Transient Analysis Model," International Journal of Heat and Mass Transfer, Vol. 37, pp. 753-762. 
10. Chang, M. and Chow, L. C., 1992, "Transient Response of Liquid Metal Heat Pipes - A Comparison of Numerical and Experimental Results," Proceedings of the $8^{\text {th }}$ International Heat Pipe Conference, Beijing, China, pp. 139-147.

11. Yamamoto, T., Nagata, K., Katsuta, M., and Ikeda, Y., 1994, "Experimental Study of Mercury Heat Pipe," Experimental Thermal and Fluid Science, Vol. 9, pp. 39-46.

12. El-Genk, M. S. and Huang, L., 1993, “An Experimental Investigation of the Transient Response of a Water Heat Pipe," International Journal of Heat and Mass Transfer, Vol. 36, pp. 3823-3830.

13. El-Genk, M. S., Huang, L., and Tournier, J. M., 1995, "Transient Experiments of an Inclined Copper-Water Heat Pipe," AIAA Journal of Thermophysics and Heat Transfer, Vol. 9, pp. 109-116.

14. Huber, N. F. and Bowman, W. J., 1996, "Longitudinal Vibration Effects on a Copper/Water Heat Pipe's Capillary Limit," AIAA Journal of Thermophysics and Heat Transfer, Vol. 10, pp. 90-96.

15. Wirsch, P. J. and Thomas, S. K., 1996, "Performance Characteristics of a Stainless Steel/Ammonia Loop Heat Pipe,” AIAA Journal of Thermophysics and Heat Transfer, Vol. 10, pp. 326-333.

16. Kobayashi, Y., Ikeda, S., and Iwasa, M., 1996, "Evaporative Heat Transfer at the Evaporative Section of a Grooved Heat Pipe," AIAA Journal of Thermophysics and Heat Transfer, Vol. 10, pp. 83-89. 
17. Vafai, K. and Wang, W., 1992, "Analysis of Flow and Heat Transfer Characteristics of an Asymmetrical Flat Plate Heat Pipe," International Journal of Heat and Mass Transfer, Vol. 35, pp. 2087-2009.

18. Zhu, N. and Vafai, K., 1998, "Analytical Modelling of the Startup Characteristics of Asymmetrical Flat-Plate and Disk-Shaped Heat Pipes," International Journal of Heat and Mass Transfer, Vol. 41, pp. 2619-2637.

19. Unnikrishnan, V. V. and Sobhan, C. B., 1997, "Finite Difference Analysis of the Transient Performance of a Flat Heat Pipe", $10^{\text {th }}$ International Conference on Numerical Methods in Thermal Problems, Swansea, UK, pp. 391-400.

20. Whitaker, S., 1986, "Flow in Porous Media I: A Theoretical Derivation of Darcy’s Law," Transport in Porous Media, Vol. 1, pp. 3-25.

21. Sobhan, C. B., Garimella, S. V., and Unnikrishnan V. V., 2000, “A Computational Model for the Transient Analysis of Flat Heat Pipes," Procs. Inter Society Conference on Thermal and Thermomechanical Phenomena in Electronic Systems - ITHERM 2000, Las Vegas, Nevada, pp. 106-113.

22. Vadakkan, U. V., Garimella, S. V., and Sobhan, C. B., 2000, "Characterization of the Performance of Flat Heat Pipes for Electronics Applications," in Emerging Cooling Technologies in Electronic Systems, IMECE 2000, Orlando, Florida.

23. Khrustalev, D. and Faghri, A., 1996, "Enhanced Flat Miniature Axially Grooved Heat Pipe," ASME Journal of Heat Transfer, Vol. 118, pp. 261-264.

24. Um, J. Y., Chow, L. C., and Baker, K., 1994, “An Experimental Investigation of Flat Plate Heat Pipe," Fundamentals of Heat Pipes, ASME HTD-Vol. 278, pp. 21-26. 
25. Faghri, A. and Thomas, S., 1989, "Performance Characteristics of a Concentric Annular Heat Pipe: Part I-Experimental Prediction and Analysis of the Capillary Limit," ASME Journal of Heat Transfer, Vol. 111, pp. 844-850.

26. Faghri, A., 1989, "Performance Characteristics of a Concentric Annular Heat Pipe: Part IIVapor Flow Analysis," ASME Journal of Heat Transfer, Vol. 111, pp. 851-857.

27. Faghri, A., Gogineni, S, and Thomas, S., 1993, "Vapor Flow Analysis of an Axially Rotating Heat Pipe," International Journal of Heat and Mass Transfer, Vol.36, pp. 22932303.

28. Harley, C. and Faghri, A., 1995, "Two-Dimensional Rotating Heat Pipe Analysis," ASME Journal of Heat Transfer, Vol. 117, pp. 202-208.

29. Lin, L. and Groll, M., 1996, "Critical Conditions for Collapse of Annular Flow in a Rotating Heat Pipe with a Cylindrical Wall," Heat Transfer Engineering, Vol. 17, pp. 2934.

30. Lin, L. and Faghri, A., 1997, "Steady-State Performance of Rotating Miniature Heat Pipe," AIAA Journal of Thermophysics and Heat Transfer, Vol. 11, pp. 513-518.

31. Lin, L. and Faghri, A., 1998, "Condensation in Rotating Stepped Wall Heat Pipes with Hysteretic Annular Flow," AIAA Journal of Thermophysics and Heat Transfer, Vol. 12, pp. 94-99.

32. Lin, L. and Faghri, A., 1999, "Heat Transfer in Micro Region of a Rotating Miniature Heat Pipe,” International Journal of Heat and Mass Transfer, Vol. 42, pp. 1363-1369. 
33. Ponnappan, R. and He, Q., 1998, "Test Results of Water and Methanol High-Speed Rotating Heat Pipes," AIAA Journal of Thermophysics and Heat Transfer, Vol. 12, pp. 391-397.

34. Daniels, T. C. and Al-Jumaily, F. K., 1975, "Investigations of the Factors Affecting the Performance of a Rotating Heat Pipe," International Journal of Heat and Mass Transfer, Vol. 18, pp. 961-973.

35. Vafai, K., Zhu, N., and Wang, W., 1995, "Analysis of Asymmetric Disk-Shaped and FlatPlate Heat Pipes," ASME Journal of Heat Transfer, Vol. 117, pp. 209-218.

36. Zhu, N. and Vafai, K., 1996, "Optimization Analysis of a Disk-Shaped Heat Pipe", AIAA Journal of Thermophysics and Heat Transfer, Vol. 10, pp. 179-182.

37. Zhu, N. and Vafai, K., 1997, "Numerical and Analytical Investigation of Vapor Flow in a Disk-Shaped Heat Pipe Incorporating Secondary Flow," International Journal of Heat and Mass Transfer, Vol. 40, pp. 2887-2900.

38. Cao, Y. and Wang, Q., 1995, "Thermal Analysis of a Piston Cooling System with Reciprocating Heat Pipes," Heat Transfer Engineering, Vol. 16, pp. 50-57.

39. Ling, J., Cao, Y., and Wang, Q., 1996, "Experimental Investigations and Correlations for the Performance of Reciprocating Heat Pipes," Heat Transfer Engineering, Vol. 17, pp. 3445.

40. Peterson, P. F. and Tien, C. L., 1990, "Mixed Double-Diffusive Convection in Gas-Loaded Heat Pipes," ASME Journal of Heat Transfer, Vol. 112, pp. 78-83.

41. Harley, C. and Faghri, A., 1994, "Transient Two-Dimensional Gas Loaded Heat Pipe Analysis," ASME Journal of Heat Transfer, Vol. 116, pp. 716-723. 
42. Ponnappan, R. and Chang, W. S., 1994, "Startup Performance of a Liquid-Metal Heat Pipe in Near-Vacuum and Gas-Loaded Modes," AIAA Journal of Thermophysics and Heat Transfer, Vol. 8, pp. 164-171.

43. Chung, J. H. and Edwards, D. K, 1996, "Moving Gas Effects on Heat Pipe Transient Behavior," AIAA Journal of Thermophysics and Heat Transfer, Vol. 10, pp. 76-82.

44. Cao, Y. and Faghri, A., 1991, "Transient Multidimensional Analysis of Nonconventional Heat Pipes With Uniform and Nonuniform Heat Distributions," ASME Journal of Heat Transfer, Vol. 113, pp. 995-1002.

45. Cao, Y. and Faghri, A., 1993, "Conjugate Modeling of High Temperature Nosecap and Wing Leading Edge Heat Pipes,” ASME Journal of Heat Transfer, Vol. 115, pp. 819-822.

46. Thomas, S. K., Klasing, K. S., and Yerkes, K. L., 1998, "The Effects of Transverse Acceleration-Induced Body Forces on the Capillary Limit of Helically Grooved Heat Pipes," ASME Journal of Heat Transfer, Vol. 120, pp. 441-451.

47. Bryan, J. E. and Seyed-Yagoobi, J., 1997, "Heat Transport Enhancement of Monogroove Heat Pipe with Electrohydrodynamic Pumping," AIAA Journal of Thermophysics and Heat Transfer, Vol. 11, pp. 454-460.

48. Richter, R. and Gottschlich, J. M., 1994, "Thermodynamics Aspects of Heat Pipe Operation,” AIAA Journal of Thermophysics and Heat Transfer, Vol. 8, pp. 334-340.

49. Zuo, Z. J. and Faghri, A., 1998, "A Network Thermodynamic Analysis of the Heat Pipe," International Journal of Heat and Mass Transfer, Vol. 41, pp. 1473-1484.

50. Swanson, L. W. and Peterson, G. P., 1995, "The Interfacial Thermodynamics of Micro Heat Pipes,” ASME Journal of Heat Transfer, Vol. 117, pp. 195-201. 
51. Khrustalev, D. and Faghri, A., 1995, "Heat Transfer During Evaporation on Capillary Grooved Structures of Heat Pipes," ASME Journal of Heat Transfer, Vol. 117, pp. 740747.

52. Schonberg, J. A., Dasgupta, S., and Wayner, P. C., 1995, “An Augmented Young-Laplace Model of an Evaporating Meniscus in a Microchannel with High Heat Flux," Experimental Thermal and Fluid Science, Vol. 10, pp. 163-170.

53. Pratt, D. M., Brown, J. R., and Halliman, K. P., 1998, "Thermocapillary Effects on the Stability of a Heated, Curved Meniscus," ASME Journal of Heat Transfer, Vol. 120, pp. 220-226.

54. Ha, J. M. and Peterson, G. P., 1996, "The Interline Heat Transfer of Evaporating Thin Films Along a Micro Grooved Surface," ASME Journal of Heat Transfer, Vol. 118, pp. 747-7545.

55. Ha, J. M. and Peterson, G. P., 1998, "Capillary Performance of Evaporating Flow in Micro Grooves: An Analytical Approach for Very Small Tilt Angles," ASME Journal of Heat Transfer, Vol. 120, pp. 452-457.

56. Ma, H. B., Peterson, G. P., and Peng, X. F., 1996, "Experimental Investigation of Countercurrent Liquid-Vapor Interactions and Their Effect on the Friction Factor," Experimental Thermal and Fluid Science, Vol. 12, pp. 25-32.

57. Peterson, G. P. and Ma, H. B, 1996, “Analysis of Countercurrent Liquid-Vapor Interactions and the Effect on the Liquid Friction Factor," Experimental Thermal and Fluid Science, Vol. 12, pp. 13-24. 
58. Peterson, G. P. and Ha, J. M., 1998, “Capillary Performance of Evaporating Flow in Micro Grooves: An Approximate Analytical Approach and Experimental Investigation,” ASME Journal of Heat Transfer, Vol. 120, pp. 743-751.

59. Peng, X. F., Peterson, G. P., and Lu, X. J., 1993, “Analysis of Capillary Induced Rewetting in Circular Channels with Internal Grooves," AIAA Journal of Thermophysics and Heat Transfer, Vol. 7, pp. 334-339.

60. Ochterbeck, J. M., Peterson, G. P., and Ungar, E.K., 1995, "Depriming/Rewetting of Arterial Heat Pipes: Comparison with Share-II Flight Experiment," AIAA Journal of Thermophysics and Heat Transfer, Vol. 9, pp. 101-108.

61. Kim, B. H. and Peterson, G. P., 1994, "Theoretical and Physical Interpretation of Entrainment Phenomenon in Capillary-Driven Heat Pipes Using Hydrodynamic Instability Theories," International Journal of Heat and Mass Transfer, Vol. 37, pp. 2647-2660.

62. Kihm, K. D., Kim, B. H., and Peterson, G. P., 1994, "Entrained Sprays from Meshed Interface Occurring in a Heat Pipe," AIAA Journal of Thermophysics and Heat Transfer, Vol. 8, pp. 184-187.

63. Kim, B. H. and Peterson, G. P., 1995, “ Analysis of the Critical Weber Number at the Onset of Liquid Entrainment in Capillary Driven Heat Pipes," International Journal of Heat and Mass Transfer, Vol. 38, pp. 1427-1442.

64. Imura, H., Kozai, H., and Ikeda, Y., 1994, "The Effective Pore Radius of Screen Wicks," Heat Transfer Engineering, Vol. 15, pp. 24-32.

65. McCreery, G. E., 1994, "Liquid Flow and Vapor Formation Phenomena in a Flat Heat Pipe," Heat Transfer Engineering, Vol. 15, pp. 33-41. 
66. Jang, J. H., Faghri, A., Chang, W. S., and Mahefkey, E. T., 1990, “ Mathematical Modeling and Analysis of Heat Pipe Start-Up From the Frozen State," ASME Journal of Heat Transfer, Vol. 112, pp. 586-594.

67. Ochterbeck, J. M. and Peterson, G. P., 1993, "Freeze/Thaw Characteristics of a Copper/Water Heat Pipe: Effects of Noncondensible Gas Charge," AIAA Journal of Thermophysics and Heat Transfer, Vol. 7, pp. 127-132.

68. Ochterbeck, J. M and Peterson, G. P., 1995, "Investigation of the Freezing Blowby Phenomenon in Heat Pipes," AIAA Journal of Thermophysics and Heat Transfer, Vol. 9, pp. 314-320.

69. Tournier, J. M. and El-Genk, M. S., 1996, “A Vapor Flow Model for Analysis of FluidMetal Heat Pipe Startup from a Frozen State," International Journal of Heat and Mass Transfer, Vol. 39, pp. 3767-3780.

70. Faghri, A., Buchko, M., and Cao, Y., 1991, “A Study of High-Temperature Heat Pipes With Multiple Heat Sources and Sinks: Part I-Experimental Methodology and Frozen Startup Profiles," ASME Journal of Heat Transfer, Vol. 113, pp. 1003-1009.

71. Faghri, A., 1992, "Frozen Start-up Behavior of Low-Temperature Heat Pipes," International Journal of Heat and Mass Transfer, Vol. 35, pp. 1681-1694.

72. Cao, Y. and Faghri, A., 1992, “Closed-Form Analytical Solutions of High-temperature Heat Pipe Startup and Frozen startup Limitation," ASME Journal of Heat Transfer, Vol. 114, pp. 1028-1035.

73. Faghri, A., Buchko, M., and Cao, Y., 1991, “A Study of High-Temperature Heat Pipes With Multiple Heat Sources and Sinks: Part II-Analysis of Continuum Transient and 
Steady State Experimental Data With Numerical Predictions," ASME Journal of Heat Transfer, Vol. 113, pp. 1010-1016.

74. Ponnappan, R., 1989, "Studies on the Start Up Transients and Performance of a Gas Loaded Sodium Heat Pipe,” Technical Report, WRDC-TR-89-2046, Universal Energy Systems, Inc., Dayton, OH.

75. Cao, Y. and Faghri, A., 1993, "Simulation of the Early Startup Period of High-Temperature Heat Pipes From the Frozen state by a Rarefied Vapor Self-Diffusion Model," ASME Journal of Heat Transfer, Vol. 115, pp. 239-246.

76. Cao, Y. and Faghri, A., 1993, “A Numerical Analysis of High-Temperature Heat Pipe Startup From the Frozen State," ASME Journal of Heat Transfer, Vol. 115, pp. 247-254.

77. Faghri, A. and Buchko, M., 1991, "Experimental and Numerical Analysis of LowTemperature Heat Pipes With Multiple Heat Sources," ASME Journal of Heat Transfer, Vol. 113, pp. 728-734.

77. Jang, J. H., 1995, "Startup Characteristics of a Potassium Heat Pipe from the Frozen State," AIAA Journal of Thermophysics and Heat Transfer, Vol. 9, pp. 117-122.

79. Schmalhofer, J. and Faghri, A., 1993, “A Study of Circumferentially-Heated and BlockHeated Heat Pipes-I. Experimental Analysis and Generalized Analytical Prediction of Capillary Limits," International Journal of Heat and Mass Transfer, Vol. 36, pp. 201-212.

80. Schmalhofer, J. and Faghri, A., 1993, "A Study of Circumferentially-Heated and BlockHeated Heat Pipes-II. Three-Dimensional Numerical Modeling as a Conjugate Problem," International Journal of Heat and Mass Transfer, Vol. 36, pp. 213-226. 
81. Tanaka, O., Koshino, H., Kuriki, J., Yohmatsu, Y., and Harada, O., 1995, "Heat Extraction from the Ground in a Volcanic Zone using Copper Water Heat Pipes - Experiment and Analysis,” Experimental Thermal and Fluid Science, Vol. 11, pp. 72-76.

82. McGuinness, M. J., 1996, "Steady Solution Selection and Existence in Geothermal Heat Pipes-I. The Convective Case," International Journal of Heat and Mass Transfer, Vol. 39, pp. 259-274.

83. Schlitt, R., 1995, "Performance Characteristics of Recently Developed High-Performance Heat Pipes," Heat Transfer Engineering, Vol. 16, pp. 44-52.

84. Ambrose, J. H., Field, A. R., and Holmes, H. R., 1995, “A Pumped Heat Pipe Cold Plate for High-Flux Applications," Experimental Thermal and Fluid Science, Vol. 10, pp.156162.

85. Dickinson, T. J., Bowman, W. J., and Stoyanof, M., 1998, "Performance of Liquid Metal Heat Pipes During a Space Shuttle Flight," AIAA Journal of Thermophysics and Heat Transfer, Vol. 12, pp. 263-269.

86. Wei, J., Hijikata, K., and Inoue, T., 1997, "Fin Efficiency Enhancement Using a Gravity Assisted Planar Heat Pipe,” International Journal of Heat and Mass Transfer, Vol. 40, pp. 1045-1051.

87. Zhao, Z. and Avedisian, C. T., 1997, "Enhancing Forced Air Convection Heat Transfer from an Array of Parallel Plate Fins Using a Heat Pipe," International Journal of Heat and Mass Transfer, Vol. 40, pp. 3135-347. 
88. Cao, Y., Faghri, A., and Mahefkey, E. T., 1993, "Micro/Miniature Heat Pipes and Operating Limitations," Heat Pipes and Capillary Pumped Loops, ASME HTD-Vol. 236, pp. 55-62.

89. Babin, B. R., Peterson, G. P., and Wu, D., 1990, "Steady State Modeling and Testing of a Micro Heat Pipe,” ASME Journal of Heat Transfer, Vol. 112, pp. 595-601.

90. Wu, D. and Peterson, G. P., 1991, "Investigation of the Transient Characteristics of a Micro Heat Pipe," AIAA Journal of Thermophysics and Heat Transfer, Vol. 5, pp. 129-134.

91. Collier, J. C., 1981, Convective Boiling and Condensation, McGraw Hill, New York.

92. Wu, D., Peterson, G. P., and Chang, W. S., 1991, “Transient Experimental Investigation of Micro Heat Pipes," AIAA Journal Thermophysics and Heat Transfer, Vol. 5, pp. 539-544.

93. Peterson, G. P., Duncan, A. B., and Ahmed, A. S., 1991, "Experimental Investigation of Micro Heat Pipes in Silicon Wafers," Microchemical Sensors, Actuators, and Systems, ASME DSC-Vol. 32, pp. 341-348.

94. Peterson, G. P., 1992, "Investigation of Micro Heat Pipes Fabricated as an Integral Part of Silicon Wafers," Proceedings of the $8^{\text {th }}$ International Heat Pipe Conference, Beijing, China, pp. 385-395.

95. Peterson, G. P., Duncan, A. B., and Weichold, M. H., 1993, "Experimental Investigation of Micro Heat Pipes Fabricated in Silicon Wafers," ASME Journal of Heat Transfer, Vol. 115, pp. 751-756.

96. Mallik, A. K., Peterson, G. P., and Weichold, M. H., 1992, "On the Use of Micro Heat Pipe as an Integral Part of Semi-conductor Devices," ASME Journal of Electronic Packaging, Vol. 114, pp. 436-442. 
97. Mallik, A. K. and Peterson, G. P., 1995, "Steady-State Investigation of Vapor Deposited Micro Heat Pipe Arrays,” ASME Journal of Electronic Packaging, Vol. 117, pp. 75-81.

98. Peterson, G. P. and Mallik, A. K., 1995, “Transient Response Characteristics of Vapor Deposited Micro Heat Pipe Arrays,” ASME Journal of Electronic Packaging, Vol. 117, pp. 82-87.

99. Duncan, A. B. and Peterson, G. P., 1995 "Charge Optimization for a Triangular-Shaped Etched Micro Heat Pipe," AIAA Journal of Thermophysics and Heat Transfer, Vol. 9, pp. 365-368.

100. Hopkins, R., Faghri, A., and Khrustalev, D., 1999, "Flat Miniature Heat Pipes With Micro Capillary Grooves," ASME Journal of Heat Transfer, Vol. 121, pp. 102-109.

101. Khrustalev, D. and Faghri, A., 1993, “Thermal Analysis of a Micro Heat Pipe,” Heat Pipes and Capillary Pumped Loops, ASME HTD-Vol. 236, pp. 19-30.

102. Longtin, J. P., Badran, B., and Gerner, F. M., 1994, “A One-Dimensional Model of a Micro Heat Pipe During Steady-State Operation,” ASME Journal of Heat Transfer, Vol. 116, pp. 709-715.

103. Sobhan, C. B., Huang X. Y and Liu, C. Y., 2000, "Investigations on Transient and SteadyState Performance of a Micro Heat Pipe," AIAA Journal of Thermophysics and Heat Transfer, Vol. 14, pp. 161-169.

104. Peterson, G. P. and Ma, H. B., 1996, "Theoretical Analysis of the Maximum Heat Transport in Triangular Grooves: A Study of Idealized Micro Heat Pipes," ASME Journal of Heat Transfer, Vol. 118, pp. 731-739. 
105. Ma, H. B. and Peterson, G. P., 1998, “The Minimum Meniscus Radius and Capillary Heat Transport Limit in Micro Heat Pipes,” ASME Journal of Heat Transfer, Vol. 120, pp. 227233.

106. Ma, H. B. and Peterson, G. P., 1996, "Experimental Investigation of the Maximum Heat Transport in Triangular Grooves," ASME Journal of Heat Transfer, Vol. 118, pp. 740-746.

107. Ha, J. M. and Peterson, G. P., 1998, “The Heat Transport Capacity of Micro Heat Pipes," ASME Journal of Heat Transfer, Vol. 120, pp. 1064-1071.

108. Cotter, T. P., 1984, "Principles and Prospects of the Micro Heat Pipes," Proceedings of the $5^{\text {th }}$ International Heat Pipe Conference, Tsukuba, Japan, pp.328-335.

109. Chen, H., Groll, M., Rosler, S., 1992, "Micro Heat Pipe: Experimental Investigation and Theoretical Modelling," Proceedings of the $8^{\text {th }}$ International Heat Pipe Conference, Beijing, China, pp. 396-400.

110. Zhang, J., Wang, C., Yang, X., and Zhou, Z., 1992, "Experimental Investigation of the Heat Transfer Characteristics of the Micro Heat Pipes," Proceedings of the $8^{\text {th }}$ International Heat Pipe Conference, Beijing, China, pp. 416-420.

111. Zhou, J., Yao, Z., and Zhu, J., 1992, "Experimental Investigation of the Application Characteristics of Micro Heat Pipe," Proceedings of the $8^{\text {th }}$ International Heat Pipe Conference, Beijing, China, pp. 421-424.

112. Bezrodny, M. K. and Podgoretskii, V. M., 1994, "Flooding and Heat Transfer Limits in Horizontal and Inclined Two-Phase Thermosiphons," Experimental Thermal and Fluid Science, Vol. 9, pp. 345-355. 
113. Shatto, D. P., Besly, J. A., and Peterson, G. P., 1997, "Visualization Study of Flooding and Entrainment in Closed Two-Phase Thermosyphon," AIAA Journal of Thermophysics and Heat Transfer, Vol. 11, pp. 579-582.

114. Zuo, Z. J. and Gunnerson, F. S., 1994, "Numerical Modeling of the Steady-State TwoPhase Closed Thermosyphon," International Journal of Heat and Mass Transfer, Vol. 37, pp. $2715-2722$.

115. Harley, C. and Faghri, A., 1994, “Complete Transient Two Dimensional Analysis of TwoPhase Closed Thermosyphons Including the Falling Condensate Film," ASME Journal of Heat Transfer, Vol. 116, pp. 418-426.

116. El-Genk, M. S. and Saber, H. H., 1999, "Determination of Operation Envelope for Closed, Two-Phase Thermosyphons," International Journal of Heat and Mass Transfer, Vol. 42, pp. 889-903.

117. Zuo, Z. J. and Gunnerson, F. S., 1995, "Heat Transfer Analysis of an Inclined Two-Phase Closed Thermosyphon," ASME Journal of Heat Transfer, Vol. 117, pp. 1073-1075.

118. Shiraishi, M., Terdtoon, P., and Murakami, M., 1995, "Visual Study on Flow Behavior in an Inclined Two-Phase Closed Thermosyphon," Heat Transfer Engineering, Vol. 16, pp. 53-59.

119. Peterson, P. F., Elkouh, N., Lee, K. W., and Tien, C. L., 1991, "Flow Instability and Bifurcation in Gas-Loaded Reflux Thermosyphons," ASME Journal of Heat Transfer, Vol. 113 , pp. 158-165.

120. Zhou, X. and Collins, R. E., 1995, "Condensation in a Gas-Loaded Thermosyphon," International Journal of Heat and Mass Transfer, Vol. 38, pp. 1605-1617. 
121. Kishimoto, T. and Harada, A., 1994, "Two-Phase Thermosyphon Cooling for High-Power Multichip Modules,” IEICE Transactions on Electronics, Vol. E77-C, pp. 986-994.

122. Lock, G. S. H. and Fu, J., 1993, "Observations on an Evaporative, Elbow Thermosyphon," ASME Journal of Heat Transfer, Vol. 115, pp. 501-503.

123. Lock, G. S. H. and Fu, J., 1993, "Heat Transfer Characteristics of a Cranked Evaporative Thermosyphon," International Journal of Heat and Mass Transfer, Vol. 36, pp. 1827-1832.

124. Lock, G. S. H. and Fu, J., 1993, "Natural Convection in the Inclined, Cranked Thermosyphon,” ASME Journal of Heat Transfer, Vol. 115, pp. 166-172.

125. Lock, G. S. H., 1992, “The Tubular Thermosyphon,” Oxford University Press, U.K.

126. Lin, L., Groll, M., and Rosler, S., 1996, "One-Dimensional Analysis of Maximum Performance in a Closed Two-Phase Thermosyphon with a Crossover Flow Separator," Heat Transfer Engineering, Vol. 17, pp. 19-28.

127. Islam, M. A., Monde, M., Hasan, M. Z., and Mitsutake, Y., 1998, "Experimental Study of Critical Heat Flux in Concentric-Tube Open Thermosyphon," International Journal of Heat and Mass Transfer, Vol. 41, pp. 3691-3704.

128. Ku, J., 1993, “Overview of Capillary Pumped Loop Technology," Heat Pipes and Capillary Pumped Loops, ASME HTD-Vol. 236, pp. 1-17.

129. Anderson, W. G., 1993, "High Temperature Capillary Pumped Loops," Heat Pipes and Capillary Pumped Loops, ASME HTD-Vol. 236, pp. 93-101.

130. Cao, Y. and Faghri, A., 1994, “Conjugate Analysis of a Flat-Plate Type Evaporator for Capillary Pumped Loops With Three-Dimensional Vapor Flow in the Groove," International Journal of Heat and Mass Transfer, Vol. 37, pp. 401-409. 
131. Dickey, J. T. and Peterson, G. P., 1994, "Experimental and Analytical Investigation of a Capillary Pumped Loop,” AIAA Journal of Thermophysics and Heat Transfer, Vol. 8, pp. 602-607.

132. Muraoka, I., Ramos, F. M. and Vlassov, V. V., 1998, "Experimental and Theoretical Investigation of a Capillary Pumped Loop with a Porous Element in the Condenser," International Communications in Heat and Mass Transfer, Vol. 25, pp. 1085-1094.

133. Boo, J. H. and Chun, M. S., 1998, "Effect of Mesh Size in a Flat Evaporator and Condenser Cooling Capacity on the Thermal Performance of a Capillary Pumped Loop,” ASME HTDVol. 361-3, pp. 121-127.

134. Bazzo, E., Colle, S. and Groll, M., 1999, “Theoretical and Experimental Study of a CPL using Freon 11 as the Working Fluid," Journal of the Brazilian Society of Mechanical Sciences, Vol. 21, pp. 17-28.

135. Krotiuk, W. J., 1997, "Engineering Testing of the Capillary Pumped Loop Thermal Control System for the NASA EOS-AM Spacecraft," Proceedings of the $32^{\text {nd }}$ Intersociety Energy Conversion Engineering Conference, Honolulu, HI, USA, Vol.2, Part 2, pp.1463-1469.

136. Bugby, D. C., Kroliczek, E. J., Cullimore, B. A. and Baumann, J. E., 1997, “Experimental Investigation of a Neon Cryogenic Capillary Pumped Loop," Proceedings of the $32^{\text {nd }}$ Intersociety Energy Conversion Engineering Conference, Honolulu, HI, Vol. 2(2), pp. 1403-1408. 


\section{Figure Captions}

Fig. 1 Axial variations of temperature, pressure, velocity and density in a sodium heat pipe at steady state [1].

Fig. 2 Transient variation of the averaged vapor temperature and pressure during heat pipe startup [6]; periodic oscillations in transient pressure variation are noted.

Fig. 3 Transient variation of the extent of liquid pool at the end of the condenser section in a water heat pipe [9].

Fig. 4 Distributions of the vapor and liquid pressure along an asymmetrical flat plate heat pipe heated only from one side [17].

Fig. 5 Transient analysis of a flat heat pipe [19]: (a) distributions of the vapor temperature, pressure and velocity for various wick porosities; (b) distributions of temperature and pressure in the wick for various wick porosities.

Fig. 6 Effect of application of a porous copper coating on the inter-groove region of a flat miniature heat pipe for enhancement of its performance, shown in comparison with the performance of a similar heat pipe without the coating: variation of the maximum heat transfer with respect to the operating temperature [23].

Fig. 7 Evaporator and condenser performance for a concentric annular heat pipe from experiments on a copper-water system [25].

Fig. 8 Condensation heat transfer coefficient as a function of heat transfer rate and rotational speed, in a rotating stepped wall heat pipe with hysteretic annular flow [31].

Fig. 9 Transient variations of the power throughput and the vapor and wall temperatures in a disk-shaped heat pipe [18]. 
Fig.10 Transient variation of the predicted vertical temperature distribution in a disk-shaped heat pipe during start-up [18].

Fig.11 Comparison of a semi-empirical correlation and experimental results on a reciprocating heat pipe [39].

$$
Y=\ln \left(\frac{\Delta T-\Delta T_{w}}{T_{m}}\right), \quad X=\ln \left[0.0052 \operatorname{Pr}^{0.87}\left(\frac{V_{l}}{V_{h p}}\right)^{-0.14}\left(1-\frac{V_{l}}{V_{h p}}\right)^{-0.39} \operatorname{Re}_{v}^{0.028} I_{m}^{0.5}\right]
$$

Fig.12 Mixed double-diffusive convection in a cylindrical gas loaded heat pipe [40]: comparison of the isoconcentration profiles from computations and experiments for a helium-water system, at various inclination angles.

Fig.13 Variation of thermal resistance with heat transport, for different values of radial acceleration, for a helically grooved copper-ethanol heat pipe [46].

Fig.14 Typical variation of the average evaporator vapor and liquid temperatures with time for a monogroove heat pipe with electrohydrodynamic pumping [47]; the effect of pumping in bringing down the temperature at dry out is illustrated.

Fig.15 Basic thermodynamic cycle of heat pipe operation on a temperature-entropy diagram [48].

Fig.16 Experimental and predicted friction factors in a countercurrent air-water heat pipe for various channel angles [56].

Fig.17 Propagation of the moving hot zone during high-temperature heat pipe start-up process, indicated by the vapor and wall temperatures [76]; the temperature front is steeper in the vapor than in the wall.

Fig.18 Axial distribution of the wall temperature (experiment and prediction) and centerline pressure in a block-heated heat pipe [80]. 
Fig.19 Predicted velocity variation in the radial and circumferential directions in a block-heated heat pipe [80]: (a) evaporator and (b) adiabatic sections.

Fig.20 Comparison of the performance of an uncharged and charged planar heat pipe used as a cooling fin, from experiment and analysis [86].

Fig.21 Measured thermal conductance of a trapezoidal (a) copper-water and (b) silver-water micro heat pipe as a function of evaporator temperature [89].

Fig.22 (a) Maximum chip temperature and (b) effective thermal conductivity for silicon wafers with and without integral micro heat pipes [95], as a function of input power.

Fig.23 Effective thermal resistance of a flat miniature heat pipe with micro capillary grooves [100] at an operating temperature of $90^{\circ} \mathrm{C}$ in the (a) horizontal and (b) vertical orientations.

Fig.24 Comparison of the calculated [102] and measured [89] heat transport capacity for a (a) silver-water, (b) copper-water micro heat pipe.

Fig.25 (a) Transient variation of the instantaneous effective thermal conductivity ratio and (b) dependence of the steady-state effective thermal conductivity ratio on the heat input at a constant heat transfer coefficient at the condenser, for a micro heat pipe of triangular cross section [103].

Fig.26 Effect of the adiabatic and condenser section lengths on the operation envelope of a closed two-phase thermosyphon [116].

Fig. 27 Variation of the effective thermal resistance of a capillary pumped loop with heat input for different values of adverse height difference [131]. 